\title{
The Global Arms Trade Network 1950-2007*
}

\author{
Anders Akerman ${ }^{\dagger} \quad$ Anna Larsson ${ }^{\ddagger}$
}

February 24, 2011

\begin{abstract}
We study the evolution of the global arms trade network using a detailed dataset on all international transfers of major conventional weapons over the period 1950-2007. First, we provide a careful description of the characteristics of global arms trade using tools from social network analysis. Second, we relate our findings to political regimes by studying whether differences in democratic status affect the likelihood of arms trade by estimating an empirical gravity model of trade. Our findings from the network analysis are much in line with common views of the Cold War. The data reveal that there is very little trade between the Warsaw Pact and NATO and that the Warsaw Pact is substantially more centralised than NATO, with the Soviet Union being more central to the former than the United States to the latter. We find that differences in democratic status has a negative and significant effect on the likelihood of arms trade between two countries throughout the Cold War. After the collapse of the Soviet Union, however, it is still the case that democracies are more prone to trade with other democracies and vice versa, but the reasons for this can be entirely accounted for by exporter and importer fixed effects.
\end{abstract}

Keywords: Arms Trade, Networks, Democracy, Autocracy, NATO, The Warsaw Pact JEL-classification: F19, F51, F59, P51

\footnotetext{
${ }^{*}$ We are grateful for comments and suggestions from Marco van der Leij, Erik Lindqvist, Stephen Parente, Brian Rogers, David Seim, Enrico Spolaore, Yves Zenou, seminar participants at Stockholm University, Stockholm School of Economics, University of Bologna and participants at the 11th annual conference of the ETSG in Rome 2009, the 4th Nordic Symposium in Macroeconomics in Helsinki 2010 and the EEA meetings in Glasgow 2010. We would also like to thank Pieter Wezeman at SIPRI for providing invaluable information about the background and quality of the dataset. Financial support from Jan Wallander's and Tom Hedelius' Foundation, K. Langenskiöld's foundation and Söderström's foundation is gratefully acknowledged by Akerman and Larsson, respectively.

${ }^{\dagger}$ Department of Economics, Stockholm University, SE-106 91 Stockholm, Sweden, Phone: +46 8162163 , Fax: +46 81594 82, E-mail: anders.akerman@ne.su.se.

${ }^{\ddagger}$ Department of Economics, Stockholm University, SE-106 91 Stockholm, Sweden, Phone: +46 8163568 , Fax: +46 81594 82, E-mail: anna.larsson@ne.su.se.
} 


\section{Introduction}

Armed conflict is arguably the single most important source of human suffering governed by mankind. Due to the high fixed costs and the extensive research and development involved in the production of military equipment, a global network of arms trade is a key catalyst for such conflicts. Given the security issues and moral considerations involved in arms trade, the lack of empirical evidence on the economics behind it, is striking. Who trades with whom? To what extent is arms trade strategic? Are governments concerned with the political regime of potential trading partners?

In this paper we study the evolution of the global arms trade network over the period 1950-2007. The analysis consists of two parts. First, we provide a thorough description of the characteristics of global arms trade using tools from social network analysis. Second, we study the effect of differences in polity between states on the likelihood of arms trade between them, using an empirical gravity model.

While the empirical evidence on arms trade is scarce, the Cold War inspired a theoretical literature on arms races, i.e. models of how two countries perceiving each other as threats react to increases in military expenditure or advancements in weapons technology from the perceived opponent. ${ }^{1}$ Contributions include Schelling (1960), Aumann et al. (1968), Intriligator (1975), Brito and Intriligator (1981), Levine and Smith (1995) and, more recently, Baliga and Sjöström (2004). Ayanian (1986) provides some empirical tests of theoretical predictions from the earlier literature. Levine et al. (1997) provide a thorough discussion of the economic fundamentals of arms trade in a paper with empirical features. The optimal design of arms control is modelled in Levine and Smith (1995).

Since there already exists a substantial body of literature on the driving forces behind arms trade, we do not attempt to provide a theoretical model that can explain the arms trade pattern. Instead, we hope to gain some additional insights by addressing the subject from a new perspective and by approaching the data with novel analytical methods.

Social network analysis has supplied economists with an increasingly popular toolbox for

\footnotetext{
${ }^{1}$ The general characteristics of global arms trade are carefully described by Brzoska and Pearson (1994). Buzan and Herring (1998) provide an overview of the security issues involved in arms trade.
} 
analysing complex interactions between a large number of agents, see Jackson (2008) for an overview. While standard economic models typically consider a small group of agents or countries in isolation, the strength of network analysis lies in its ability to describe and analyse the interactions in a large system that would quickly become intractable using standard models. Recently, network analysis has therefore started to gain recognition among trade economists and applied macroeconomists, see for instance De Benedictis and Tajoli (2008), who study the global trade network and Flandreau and Jobst (2005, 2009), who study the existence of strategic externalities in the international currency system.

We argue that network analysis is particularly suited for the study of arms trade for the following reasons. First, the fact that arms trade is heavily regulated allows us to think of arms traders and governments as roughly the same entity. ${ }^{2}$ Second, the moral concerns and potential repercussions involved in arms trade suggest that decisions to trade in arms are strategic. Since governments are likely to choose its trading partners with great care, the arms trade network is therefore likely to reflect a network of political ties and alliances. Using network theory, we are able to identify key players with central positions in the network and study how their roles have changed over time. Specifically, we are able to identify important differences and similarities between the two intergovernmental military alliances dominating the post-war era, i.e. the North Atlantic Treaty Organization (NATO) and the Warsaw Pact.

One key result from the network analysis is that there is a clear ideological divide in the international arms trade network during the Cold War. This begs the question of whether political regimes affect the likelihood of arms trade. Following the descriptive network analysis, we therefore study the impact of differences in political regimes on the likelihood of arms trade by adding factors capturing distance in polity and institutional measures to a gravity equation. ${ }^{3}$ There are many reasons to believe that polity matters when choosing arms trade partners. A number of scholars subscribe to what is known as the Democratic Peace Theory (DPT), see for instance Maoz and Russett (1993), de Mesquita et al. (1999), Kadera et al. (2003) and Levy

\footnotetext{
${ }^{2}$ As explained more carefully later, we exclude trade in small arms from the analysis due to considerable lack of data and the fact that governments have much less control over these types of weapons.

3 We are well aware of the fact that, when studying political regimes and arms trade, causality may run in both directions. In this paper, we therefore intepret our results with some caution and leave the issue of causality to a follow-up paper.
} 
and Razin (2004). According to this hypothesis, two democratic states are extremely unlikely to engage in militarised conflict with each other. The DPT thus suggests that a democratic state is more apt to sell arms to another democratic state than to a non-democratic state since the probability of an armed conflict is higher with the latter than the former. ${ }^{4}$

We use a unique dataset from the Swedish Institute for Peace Research (SIPRI), covering all trade in military equipment over the period 1950-2007. We feel confident that the dataset is the richest dataset available on arms trade and have been assured of its high quality. ${ }^{5}$ To the best of our knowledge, our paper is the first to apply the aforementioned methodology on any dataset on arms trade and political regimes.

Our main findings are as follows. In the first part of the analysis, we find that while the global arms trade network possesses some characteristics typically found in empirical studies of other networks, we are also able to identify some important differences. Similar to other networks, we find that the global arms trade network exhibits a small-world property, negative correlation between degree and clustering coefficients and can be described by a scale-free degree distribution. The network is also characterised by negative assortativity, a feature found in other trade networks as described by De Benedictis and Tajoli (2008). Our results suggest that the most central countries in the network are very influential. Moreover, there are large changes in key characteristics over time. The network as a whole becomes denser over time as an increasing number of countries start trading in arms and, additionally, form more links. In terms of network characteristics, there are substantial differences between NATO and the Warsaw Pact. Throughout the Cold War, the NATO network is more decentralised than the Warsaw Pact and the largest trader within NATO, the US, is less influential than the largest trader in the Warsaw Pact, the Soviet Union. We believe these findings to be in line with how most people have come to view the hierarchy within the two organisations during the Cold War.

\footnotetext{
${ }^{4}$ Mulligan et al. (2004) find that military expenditures are typically higher in autocracies than in democracies, and suggest that democratic leaders have less reason to worry about foreign military threats than a dictator. As noted by Cowen (1990), a democratic leader is likely to go to war if he thinks that international victories will strengthen his probability of reelection and, as pointed out by Mulligan et al. (2004), a democratic leader is more likely to attack a regime that his electorate resents.

${ }^{5}$ Trade in small arms is excluded from the dataset. Since illegal trade is very difficult for larger types of military equipment, the exclusion of small arms implies that we face a very small risk of measurement error.
} 
In the second part of the analysis, we find that the largest arms exporters tend to trade arms with countries with similar political rule. The largest democracies export to democracies as well as autocracies but, with some exceptions, they tend to favour democracies. The largest autocracies have an even stronger bias towards other autocracies. To control for factors such as geographic proximity and colonial ties, we add distance in polity to a gravity-equation with the likelihood of arms trade as the dependent variable. We find that there is a stable negative relationship between differences in polity and the likelihood of arms trade. The relationship is stable for the duration of the Cold War. Following the collapse of the Soviet Union in 1991, however, the inclusion of exporter and importer fixed effects renders polity insignificant. Since importer and exporter fixed effects capture such characteristics as the size of the arms industry and proximity to unstable territories, our findings suggest that, during the Cold War, countries chose to trade arms with countries with similar political regimes irrespective of the country features captured by the fixed effects. After the collapse of the Soviet Union, our findings indicate that while arms trade links continue to be formed among countries within the same political vicinity, the likelihood to trade is entirely driven by country specific fixed effects capturing features unrelated to the political regime per se.

The paper is organised as follows. Section 2 provides a descriptive analysis of the evolution of the global arms trade network using social network theory. Section 3 addresses the issue of polity and arms trade by reporting the results from estimating a gravity model. Section 4 concludes.

\section{The Global Arms Trade Network}

In this section we study the evolution of the global arms trade network over time. We begin with a discussion of the SIPRI dataset in Section 2.1. We then aggregate arms trade between countries over five-year intervals and graph the global arms trade in section 2.2. We then define key centrality measures in Section 2.3. The evolution of these measures over time are reported in Sections 2.4 and 2.5.

Throughout the section we study (i) all countries trading arms, (ii) countries trading arms with at least one full member of NATO (we call this set of countries the NATO Network) and 
(iii) countries trading arms with at least one full member of the Warsaw Pact (the Warsaw Pact Network). ${ }^{6}$

\subsection{Data}

SIPRI hosts 6 different databases related to international relations, military expenditure, production and arms trade. The data used in this study is obtained from the SIPRI Arms Transfers Database, holding information on all international transfers of seven categories of Major Conventional Weapons from 1950 onwards. The concept of Major Conventional Weapons comprises aircraft, armoured vehicles, artillery, sensors, air defence systems, missiles, ships, engines (for military aircraft, combat ships and most armoured vehicles) and other major conventional weapons (mainly turrets for armoured vehicles and ships). ${ }^{7}$

Our measure of arms trade is total bilateral exports (imports) of Major Conventional Weapons over the period 1950-2007. In order to minimise the noise in the data, we have chosen to eliminate rebel groups from the sample. Discussions with representatives of SIPRI have ensured us of the high quality of the dataset. We have learned that, since the rules and surveillance pertaining to arms are so strict and since equipment of this nature and size is difficult to hide from observation, arms trade not captured by the dataset is negligible. ${ }^{8}$

\footnotetext{
${ }^{6}$ During the decade following World War II, the majority of the industrialised world was roughly divided into two defense alliances. The North Atlantic Treaty Organization (NATO) was founded on April 41949. The Treaty of Friendship, Cooperation and Mutual Assistance, commonly referred to as the Warsaw Pact, was founded on May 17 in 1955 and disestablished on July 1 in 1991. The member countries of NATO and the Warsaw Pact are listed in Table A1 in the Appendix.

7 The standard dataset for international trade, the United Nations' Comtrade dataset, also includes trade in arms, more specifically "Arms and ammunitions" (sector 891 under SITC Rev. 4). We believe, however, that the SIPRI dataset is much more suitable for this analysis for two main reasons. First, the UN data is collected by national customs authorities and therefore susceptible to political manipulation due to the nature of these goods. The SIPRI, on the other hand, collects its data from a much wider range of sources and is completely transparent as regards the exact content of any trade. Second, the UN data contains many "dual use" goods which are suitable for both civilian and military use. An example would be optical equipment that can be used separately as binoculars or mounted on rifles. The SIPRI data is much more focused on larger types of goods and on items intended exclusively for military use.

8 The entire arms trade network remains connected throughout the sample period except for one trade in 2000 between Cap Verde and Malawi where this pair is isolated from the rest of the network. We choose to drop these two countries from the sample which results in a negligible loss of 22 out of 14,343 observations in the sample.
} 


\subsection{Graphs of The Arms Trade Network}

In order to be able to graph the evolution of the arms trade network over time, we first compute five-year averages of bilateral arms trade and plot them. ${ }^{9}$ Figure 1 displays the arms trade network over the period 1950-1954 and Figure 2, the network over the period 1970-1974. ${ }^{10}$ Due to space constraints we only include a selection of graphs in the paper, but all omitted plots are available on request. In these graphs, each node represents a country and each link indicates that there is trade between the two countries in question. The length of each link is thus not proportional to the magnitude of the trade, they simply indicate whether trade has occurred during the period. The arrows run from exporter to importer.

Figure 1, covering the period 1950-1954, shows that during this period, global arms trade is roughly divided into two networks. The first network is centered around the US and the other around the USSR. A similar patter, albeit much more complex, holds for the 1970-1974 network in Figure 2. This pattern is preserved throughout the Cold War, but the divide between the two groups is particularly clear in the 1950s. In general, the plots suggest that the arms trade network becomes much more dense and complex over time. After the collapse of the Cold War and the disestablishment of the Warsaw Pact, the divide between the two groups is much less distinct. An example of this is given in Figure 3, displaying the arms trade network over the period 2000-2004. The graph suggest that the network has become even denser in recent years and it is difficult, if not impossible, to detect the East-West division of the 1950s.

\subsection{Network theory: Definitions and Key Concepts}

We next describe some key statistics for characterising the evolution of the arms trade network over time. Let $N=\{1, \ldots, n\}$ denote the set of nodes in the network. Each node represents a country. Let $g$ represent an $n \times n$ matrix where $g_{i j}$ represents the link between countries $i$ and

\footnotetext{
${ }^{9}$ We choose to illustrate five-year averages simply due to space constraints.

${ }^{10}$ All network graphs are processed using the Pajek software. We use the Kamada-Kawai method of energising the data for the layouts as this seems to produce more stable results than for instance the Fruchterman Reingold energy command; see de Nooy et al. (2005).
} 


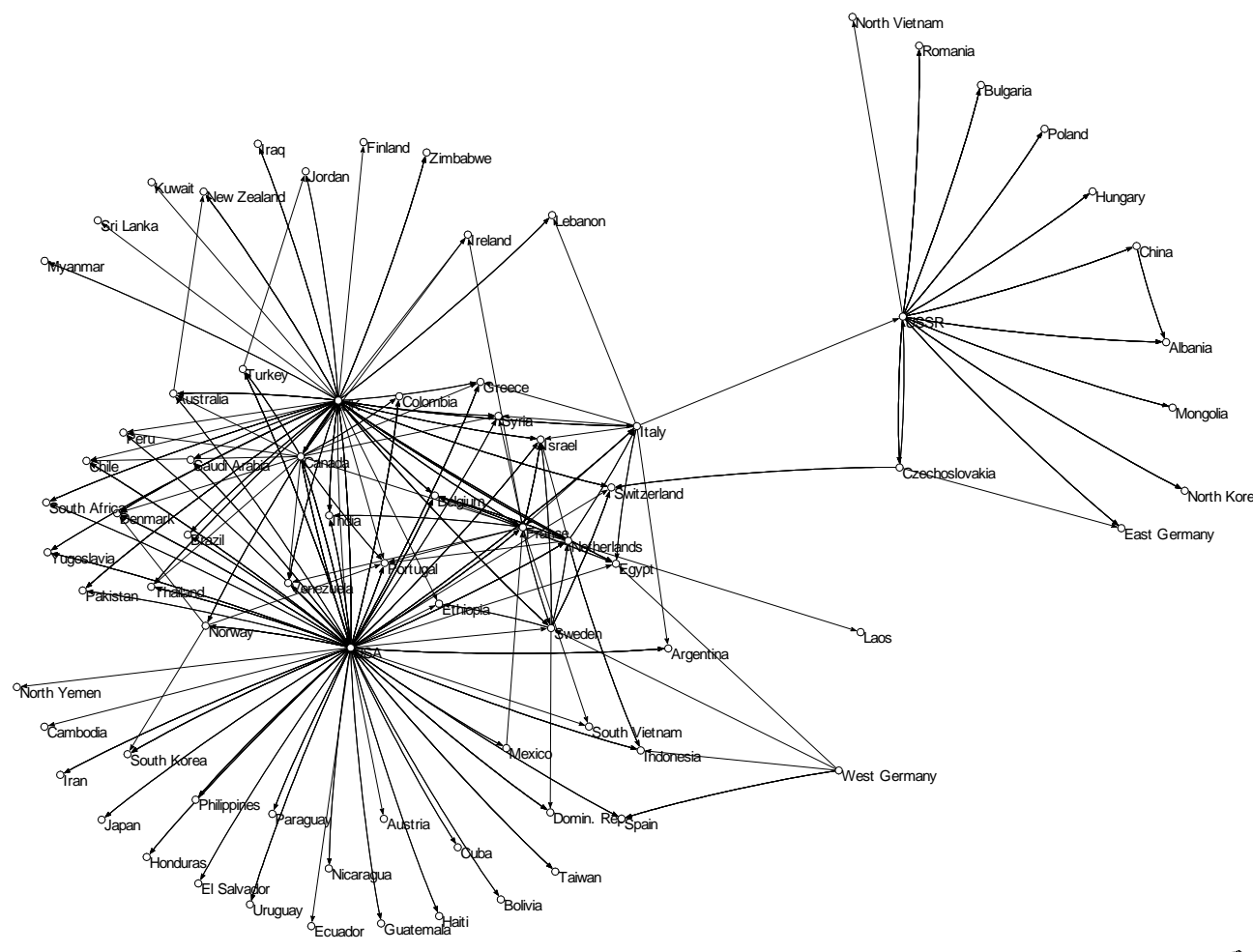

Figure 1: The global arms trade network, 1950-1954.

$j$. For our purposes, it is the existence of arms trade rather than the magnitude of the trade that matters, and we therefore think of each link as having equal strength. In other words, we think of the network as being unweighted and define

$$
g_{i j}=\left\{\begin{array}{c}
1 \text { if } i \text { and } j \text { are trading arms } \\
0 \text { otherwise }
\end{array} .\right.
$$

The neighbourhood of a node $\mathrm{i}$ in the network $g$ is the set of nodes linked to $i$ :

$$
N_{i}(g)=\left\{j: g_{i j}=1\right\} .
$$

The degree of a node, $d_{i}(g)$, is the number of links that involve that node, i.e.

$$
d_{i}(g)=\#\left\{j: g_{j i}=1\right\}=\# N_{i}(g) .
$$

A path between nodes $i$ and $j$ is a sequence of links $i_{1} i_{2}, i_{2} i_{3}, \ldots, i_{K-1} i_{K}$ such that $i_{k} i_{k+1} \in g$ $\forall k \in\{1, \ldots, K-1\}$ with $i_{1}=i$ and $i_{K}=j$, and such that each node in the sequence $i_{1}, \ldots i_{K}$ 


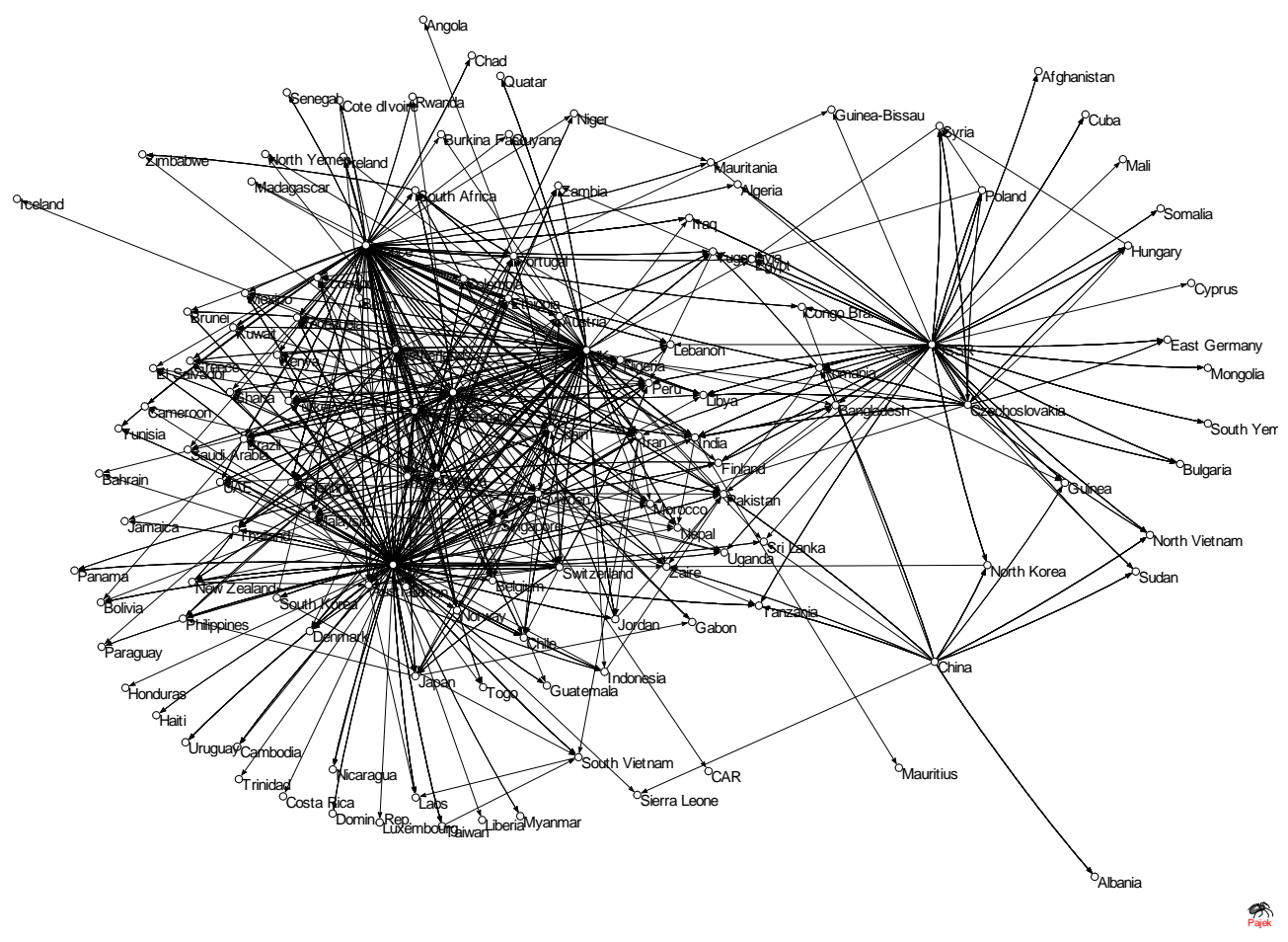

Figure 2: The global arms trade network, 1970-1974.

is distinct. A path never hits the same node twice. The distance between two nodes is the number of links in the shortest path (geodesic) between them. For future reference, denote the distance between $i$ and $j$ by $l(i, j)$.

We next define key micro statistics pertaining to individual nodes. These concepts are important in identifying and characterising important players in the network. It is useful to start with a description of these individual characteristics as some of the definitions are needed when describing the properties of the network at large.

Degree Centrality The degree centrality of country $i$ is computed as

$$
C e_{i}^{D}(g)=\frac{d_{i}(g)}{n-1} .
$$

A country with degree $n-1$ would be trading arms with every other country in the network. By contrast, a country with a low degree would be considered less central. Since the maximum 


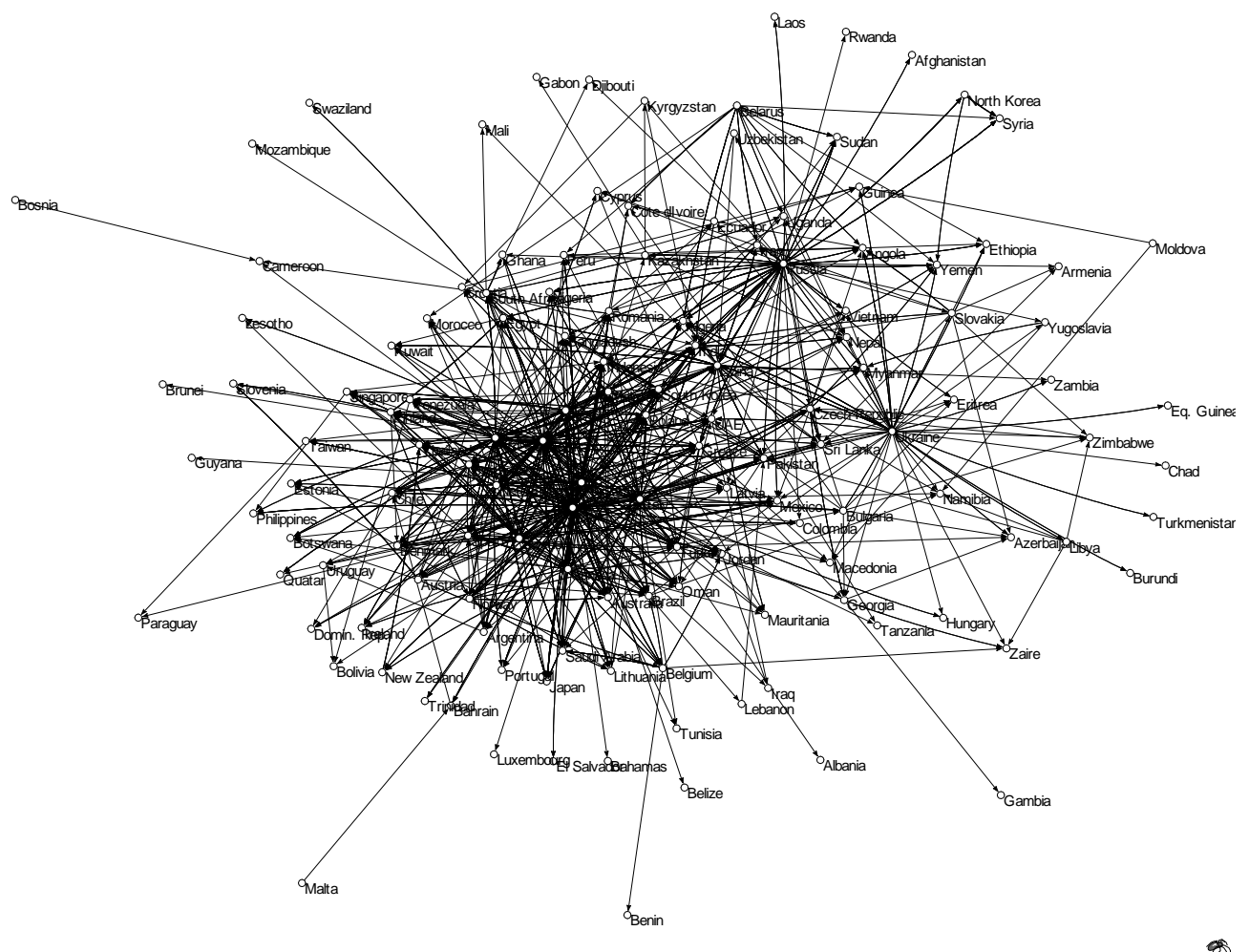

Figure 3: The global arms trade network, 2000-2004.

degree is $n-1$, the measure of degree centrality is confined within the unit interval.

The degree centrality-measure has some shortcomings. While it does provide some indication of connectedness, it says nothing about how close each node is to other nodes or about the location in the network.

Closeness Centrality Closeness centrality tracks how close a node $i$ is to any other node $j$ in the network. Recall that $l(i, j)$ denotes the number of links in the shortest path between $i$ and $j$. Closeness centrality is defined as

$$
C e_{i}^{C}=\frac{n-1}{\sum_{j \neq i} l(i, j)} .
$$

Closeness centrality thus measures the inverse average distance between $i$ and $j$. 
Betweenness Centrality Let $P_{i}(j k)$ denote the number of shortest paths between nodes $j$ and $k$ that $i$ lies on and let $P(j k)$ be the total number of shortest paths between $j$ and $k$. The ratio $P_{i}(j k) / P(j k)$ captures the importance of $i$ in connecting $j$ and $k$. If $P_{i}(j k) / P(j k)$ is close to one, country $i$ lies on most of the geodesics between $j$ and $k$. If the ratio is close to zero, country $i$ is less important in connecting $j$ and $k$. Betweenness centrality is defined as

$$
C e_{i}^{B}=\sum_{j \neq k: i \notin\{j, k\}} \frac{P_{i}(j k) / P(j k)}{(n-1)(n-2) / 2} .
$$

Betweenness centrality is thus a measure of the ratio of $P_{i}(j k) / P(j k)$, averaged across all pairwise nodes $j$ and $k$ that meet the above criteria.

We next define some key statistics that are useful when attempting to characterise the network as a whole.

Diameter The diameter of the network is the largest distance between any two nodes in the network. It thus provides an upper-bound measure of the size of the network.

Density The density of the network is computed as the average degree divided by $n-1$, i.e.

$$
D(g)=\frac{\sum_{i} d_{i}(g)}{n(n-1)}
$$

Degree Distribution The degree distribution, $P(d)$, of the network captures the relative frequencies, i.e. fractions of nodes that have different degrees, $d$. A power distribution (scalefree distribution) satisfies:

$$
P(d)=c d^{-\gamma}
$$

where $c>0$ normalises the support of $P$ to sum to 1 . Taking logs we obtain:

$$
\log (P(d))=\log c-\gamma \log d
$$

Using actual data on the observed distribution of degrees, $\gamma$ can be estimated from this formulation. 
Overall Clustering Clustering coefficients describe how connected nodes in the network are. Overall clustering of the network is defined as

$$
C l(g)=\frac{\sum_{i} \#\left\{j k \in g \mid k \neq j, j \in N_{i}(g), k \in N_{i}(g)\right\}}{\sum_{i} \#\left\{j k \mid k \neq j, j \in N_{i}(g), k \in N_{i}(g)\right\}}=\frac{\sum_{i ; j \neq i ; k \neq j ; k \neq i} g_{i j} g_{i k} g_{j k}}{\sum_{i ; j \neq i ; k \neq j ; k \neq i} g_{i j} g_{i k}} .
$$

To understand this concept, consider two nodes, $i j$ and $i k$, sharing the common node $i$. The measure of average clustering measures how common it is that also the nodes $j$ and $k$ are linked to each other.

Average Clustering In order to compute the average clustering coefficient, we first need to define individual clustering. The individual clustering coefficient is given by:

$$
C l_{i}(g)=\frac{\#\left\{j k \in g \mid k \neq j, j \in N_{i}(g), k \in N_{i}(g)\right\}}{\#\left\{j k \mid k \neq j, j \in N_{i}(g), k \in N_{i}(g)\right\}}=\frac{\sum_{j \neq i ; k \neq j ; k \neq i} g_{i j} g_{i k} g_{j k}}{\sum_{j \neq i ; k \neq j ; k \neq i} g_{i j} g_{i k}} .
$$

The individual clustering coefficient of node $i$ therefore considers all pairs of nodes that it is linked to, and then registers how many of them are linked to each other. The average clustering coefficient is then the average of all individual clustering coefficients, i.e.

$$
C l^{A v g}(g)=\sum_{i} \frac{C l_{i}(g)}{n} .
$$

Average clustering gives more weight to low-degree nodes than the overall clustering coefficient.

Max Degree The Max Degree of the network, $C e_{i}^{D *}$, is the degree of the node with the highest number of links.

Max Closeness The Max Closeness of the network, $C e_{i}^{C *}$, is the value of Closeness Centrality of the node with the highest measure of this statistic.

Max Betweenness The Max Betweenness of the network, $C e_{i}^{B *}$, is the value of Betweenness Centrality of the node with the highest measure of this statistic.

Degree Centrality The Degree Centrality of the network is given by:

$$
C e^{D}(g)=\frac{\sum_{i}\left|C e_{i}^{D}-C e_{i}^{D *}\right|}{(n-2)(n-1)} .
$$


Closeness Centrality The Closeness Centrality of the network is given by:

$$
C e_{i}^{C}=\frac{\sum_{i}\left|C e_{i}^{C}-C e_{i}^{C *}\right|}{(n-2)(n-1) /(2 n-3)} .
$$

Betweenness Centrality The Betweenness Centrality of the network is given by:

$$
C e_{i}^{B}=\sum_{i}\left|C e_{i}^{B}-C e_{i}^{B *}\right|
$$

Assortativity Turning to the correlation patterns among high-degree nodes, we turn to the concept of assortativity. If high-degree nodes tend to be connected to other high-degree nodes, there is said to be positive assortativity. The degree of assortativity of the network $g$ is computed as

$$
A(g)=\frac{\sum_{i j \in g}\left(d_{i}-m\right)\left(d_{j}-m\right)}{\sum_{i \in N}\left(d_{i}-m\right)^{2}} .
$$

\subsection{Characteristics of the Arms Trade Network}

Figure 4 plots the evolution of the statistics defined in Section 2.3 for the network including all countries. Note that we make no distinction between exporters and importers in this analysis and treat the network as if it were undirected. Starting with the aggregate properties of the network, Figure 4 suggests that the number of countries involved has increased along with the diameter and the density. This suggests that an increasing number of countries have started to trade in arms. This may be due to either an increase in the number of exporters (producers of arms) or an overall increase in import demand for arms. The graphs in Figures 1, 2 and 3 support the claim that the global arms trade network has become much more dense and complicated over time.

The number of countries that trade in arms increases rapidly during the sample period. The diameter increases as well but remains very low throughout the sample, a feature of many networks often referred to as the small world property, see for instance Goyal et al. (2006).

We see that the country with the highest number of links, as measured by max degree, is increasing in the beginning of the sample but is starting to decrease at the end of the Cold War. While overall clustering has increased, average clustering has been falling over time. The fall in average clustering results from the entrance of small, new countries, who only trade with a few 


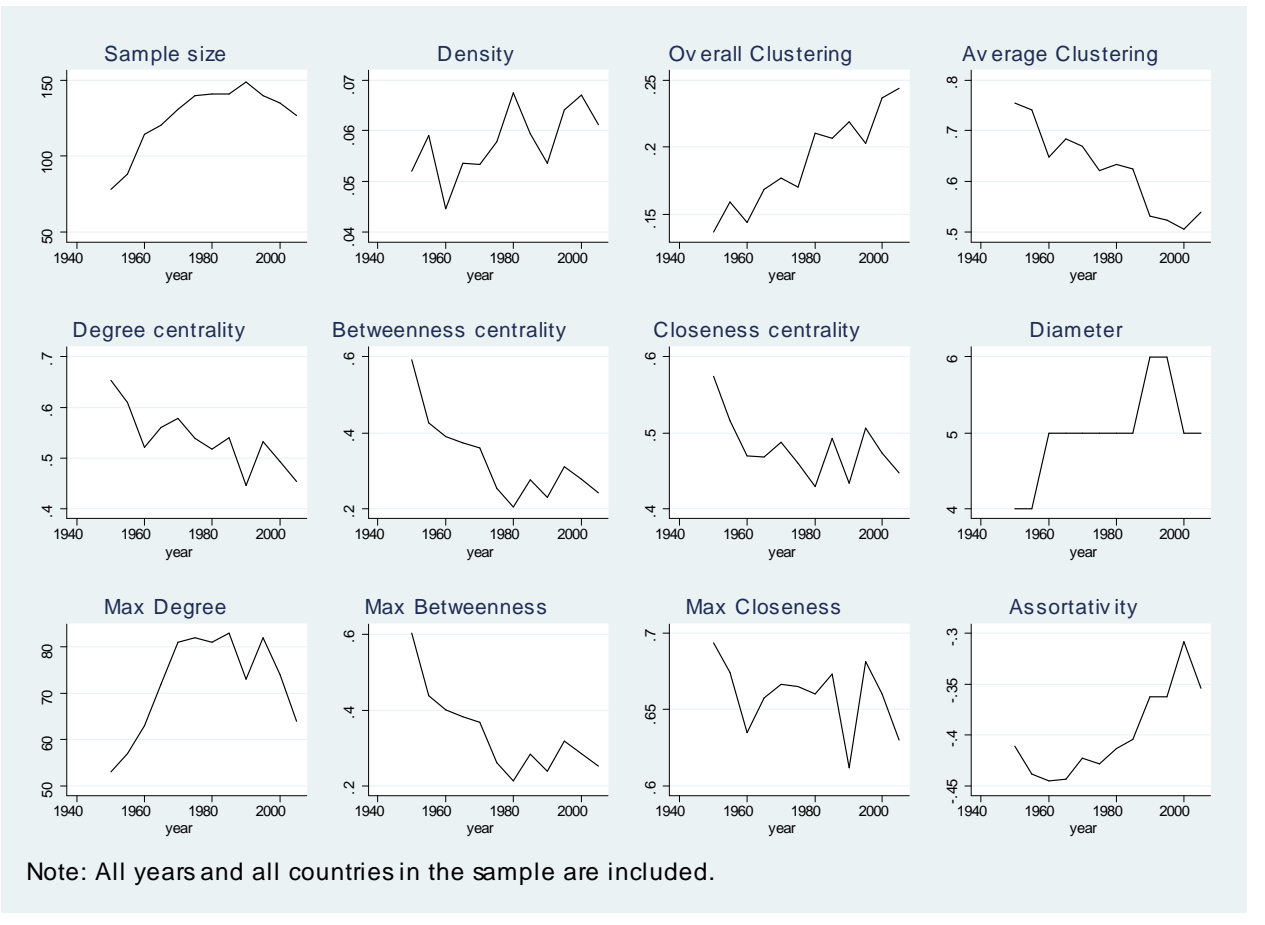

Figure 4: Network statistics for the global arms trade network.

countries who, in turn, do not trade with each other. The fact that overall clustering increases, however, is the result of the network as a whole growing denser and more connected and in particular that the countries with the highest number of links have become more clustered, i.e. that their trading partners have become more likely to trade as well. All three centrality measures are also decreasing over time, suggesting that the most important countries have become less influential over time. However, the centrality measures remain relatively high throughout the sample period. This suggests that while a small set of key countries have been able to maintain their central positions in the network throughout the period, they have become less influential over time as the network has become increasingly decentralised.

Finally, assortativity is negative throughout the sample but less so in recent years. Negative assortativity is typical for many other trade and technological networks where countries (agents) with many connections are prone to trade with countries (agents) with fewer connections. Countries with few connections, on the other hand, are more likely to trade with 


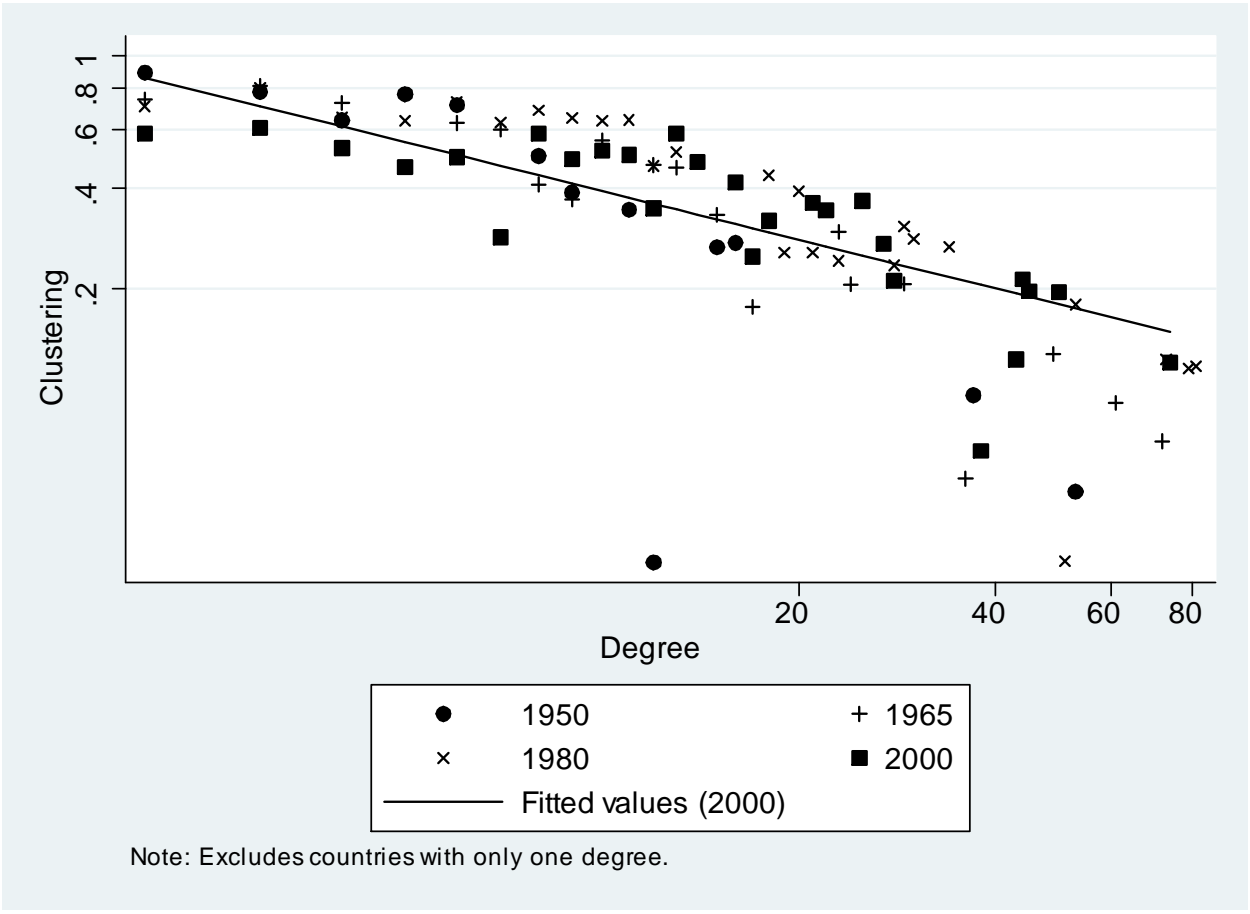

Figure 5: Average clustering and degree distribution, 1950, 1965, 1980 and 2000.

countries with many trading partners. ${ }^{11}$

Figure 5 displays the degree distribution of the global arms trade network in 1950, 1965, 1980 and 2000. The results suggest that a scale-free distribution of the Pareto type, as described by (5), would indeed characterise the network fairly well. The estimated value of $\gamma$ in (5) is around 0.9 .

Figure 6 plots the degree distribution against average clustering for the years 1950, 1965, 1980 and 2000 and the graph clearly reveals a negative relationship between the two. This suggests that the majority of the trading partners of the most active arms traders do not trade with each other, a typical feature of star networks.

We may summarise our findings for the global arms trade network as follows.

(i) The number of countries in the network rises constantly until 1990;

\footnotetext{
11 This property stands in contrast to many social networks where, for example, friends of individuals with many friends also tend to have many friends, see Newman (2002).
} 


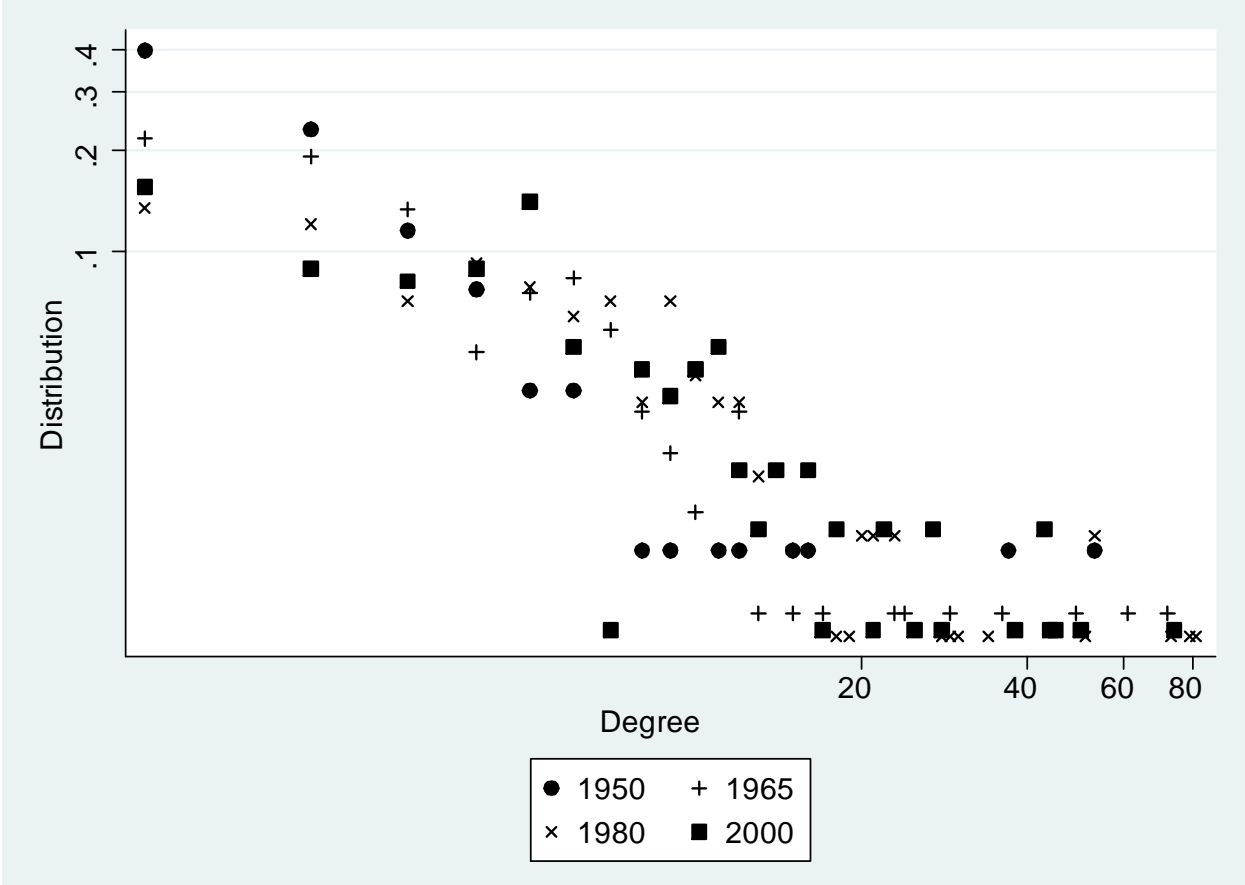

Figure 6: Degree distribution 1950, 1965, 1980 and 2000.

(ii) The network is fairly centralised with some important central countries and a large number of peripheral countries (high centrality measures, a negative relation between average clustering and number of degrees, large differences between overall and average clustering and negative assortativity);

(iii) The network becomes increasingly decentralised over time (all centrality measures are falling over time, overall clustering increases while average clustering decreases and assortativity becomes less and less negative);

(iv) The diameter remains remarkably low throughout the sample, peaking at a value of 6 , despite the fact that 150 countries participate in the network.

Figure 7 displays key network statistics for NATO and the Warsaw Pact. We see that the number of countries and the network diameter are displaying positive trends for both networks. The fact that the diameter is almost the same for the two networks despite the larger size of NATO suggests that NATO is better internally connected than the Warsaw Pact. 


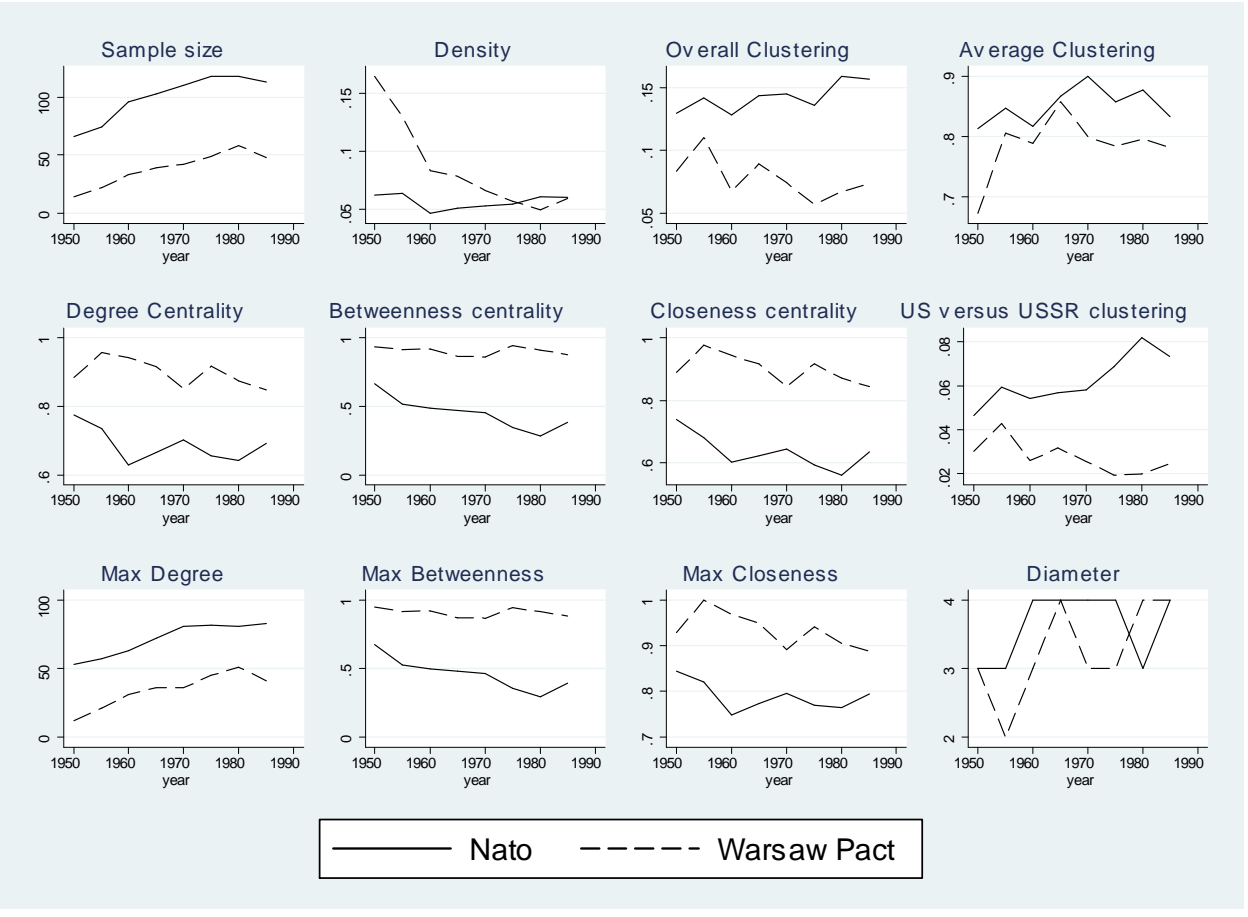

Figure 7: Network statistics for NATO and the Warsaw Pact.

While the NATO network is becoming more dense over time, the Warsaw Pact density is falling sharply up to its disestablishment in 1991. We also see that the max degree is much higher in NATO than in the Warsaw Pact, indicating that the US has more links than the USSR for the duration of the Cold War. This is hardly surprising given that NATO is larger. Regarding the centrality measures, they are all relatively stable over time but show that the Warsaw Pact was a much more centralised network than NATO. This can also be seen in the network graphs in Figure 1 where the Warsaw Pact network most clearly resembles a "star" network with one central node (the USSR) surrounded by peripheral trading partners who, as a rule, do not trade with each other. This property is also revealed by the fact that the overall clustering variable is substantially lower in the Warsaw Pact than in NATO throughout the sample. A defining property of a star network is precisely that while the central country trades with many other countries, these are unlikely to trade with each other. The fact that the USSR was more important for the Warsaw Pact than the United States was for NATO is shown by the measures of maximum centrality being higher for the Warsaw Pact than for 
NATO throughout the period.

The main differences between NATO and the Warsaw Pact can be summarised as follows.

(i) There is a distinct division between NATO and the Warsaw Pact during the Cold War, most clearly in the beginning. Towards the end of the sample, an increasing number of countries trade with both alliances.

(ii) More countries participate in the NATO network than in the network of the Warsaw Pact.

(iii) The Warsaw Pact is substantially more centralised than NATO.

(iv) The role of the USSR in the Warsaw Pact is more important than that of the United States in NATO.

(v) NATO is internally better connected and the United States is much more clustered than the USSR.

(vi) Density falls sharply for the Warsaw Pact but not for NATO.

The graphic division between NATO and the Warsaw Pact is a naive but compelling indication that polity matters for arms trade ties. It is well known that throughout the post-war era, the conflict between the US and the Soviet Union was based on radically different ideological beliefs. While the constitution in the US is based on maximum freedom of individuals, the Soviet Union has come to represent the other extreme; autocratic rule by a highly centralised government. This ideological divide seems to be mirrored in the arms trade network. The results from the network analysis suggest that the Warsaw Pact network, centered around the Soviet Union, comprises mainly other autocratic states. Conversely, the NATO network consists mainly of democratic states and is centered around the world's oldest and largest democracies; the US, the UK and France. ${ }^{12}$ While this is circumstancial evidence that, his-

\footnotetext{
12 Clearly, the dichotomous division of the world's states into autocracies and democracies is a crude approximation of reality. Since democracies as well as autocracies can be either right-wing or left-wing, it would interesting to study a more detailed classification of countries. However, this is beyond the scope of the paper and left for future research.
} 
torically, polity has been of great importance when choosing arms trade partners, we look for statistical support for this conjecture in Section 3.2, below.

\subsection{The Subset of Countries Trading in 1950}

The increasing density and complexity of the arms trade network can be due to one of two factors. It is either the case that a large number of new countries have entered the network, or that the countries that have been trading all along are forming more links and trading more with each other. This raises the concern that the decreasing importance of the divide between NATO and the Warsaw Pact is due to increasing noise rather than some fundamental change in the connections between East and West. In order to address this issue, we identify the subsample of countries that were trading in 1950 and study how this sub-network has evolved over time. Graphs of this network over the years 1970-74 and 2000-2004, respectively, are given in Figures A1 and A2 in the Appendix. Figure A2 suggests that the division between the two alliances is indeed preserved in the 1970s. While an increasing number of countries are trading with both parties, there is a clear division between the two alliances. The USSR has now lost some of its importance in the Warsaw Pact as Czechoslovakia in particular has become an important player in the East. The graph in Figure A2 corroborates the conclusions drawn from Figure 3: in recent years the east-west division has disappeared completely. North Korea and Syria are isolates and form a sub-network of their own during the period 2000-2004.

Finally, Figure A3 displays the evolution of characteristics of the 1950 sub-network. The graph suggests that the properties of the network are similar to those of the network as a whole, except for the decreasing sample size as some countries vanish from the set.

\section{Polity and Arms Trade}

Having characterised the global arms trade network and how it evolves over time, we next turn to the empirical relationship between arms trade and political regimes. We therefore add data on political and economic characteristics and estimate a gravity equation where one of the independent variables is a measure of distance in polity. 


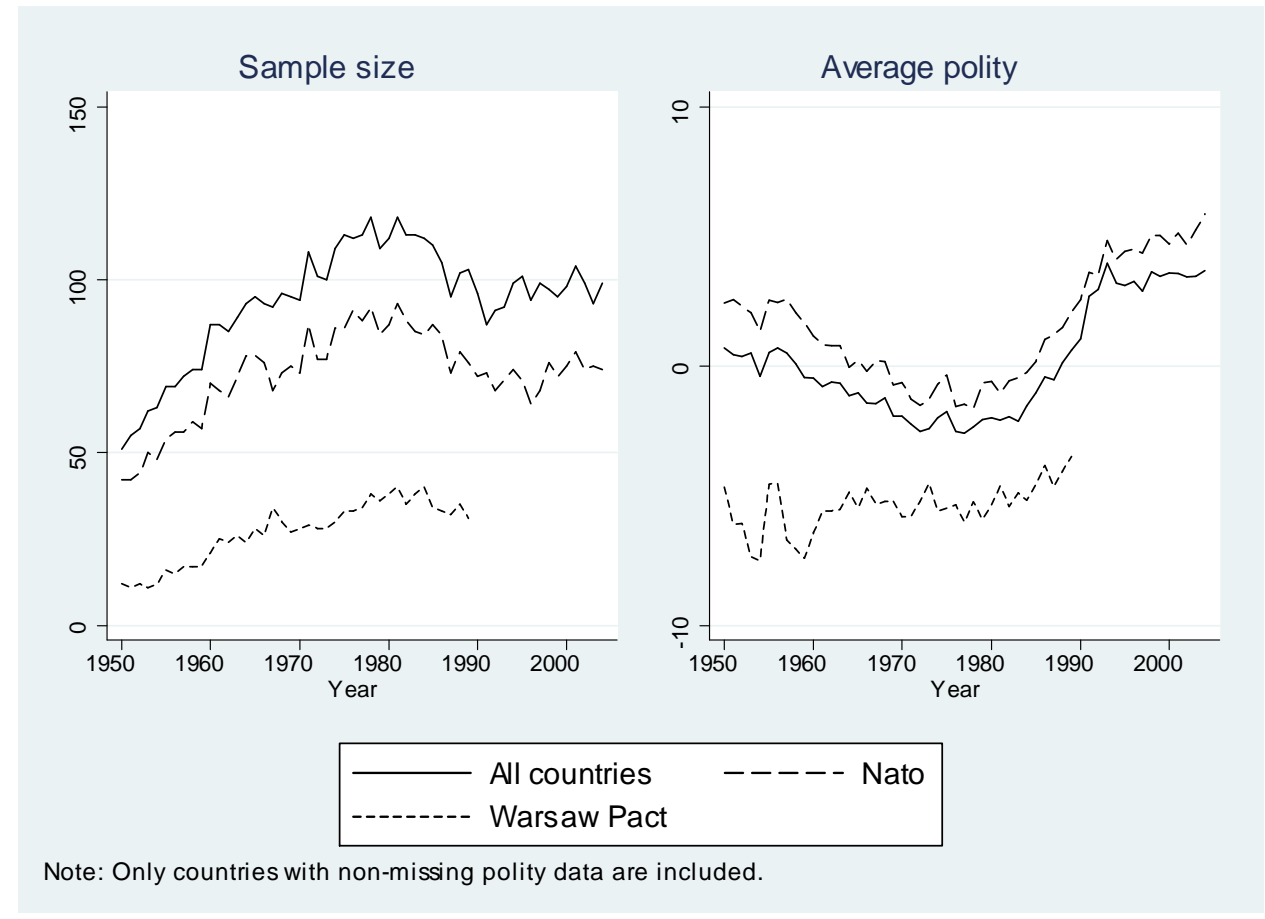

Figure 8: Arms trade participation and average polity, 1950-2007.

\subsection{Data}

Data om GDP per capita is from Maddison and covers the full sample period 1950-2006. Data on distance between countries, common language, common borders and common origin of colonisation is retrieved from Centre D'Etudes Prospectives et D'Informations Internationales (CEPII). Data on the degree of democracy is from the POLITY IV database hosted by the Center for Systemic Peace and George Mason University. The polity variable, henceforth denoted POLITY, is an index ranging from -10 to +10 , where a negative value represents autocracy and a positive value represents democracy. The higher the value, the stronger the democratic regime in terms of a number of criteria specified within POLITY IV. In order to compare our findings on arms trade to aggregate trade, we add data on trade from the United Nations Comtrade database over the period 1962-2000. 

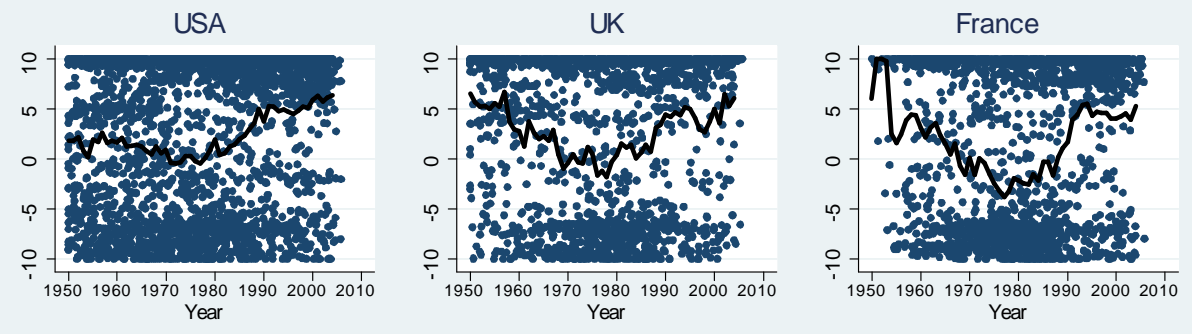

Sw eden

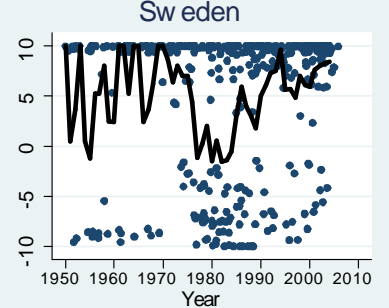

USSR
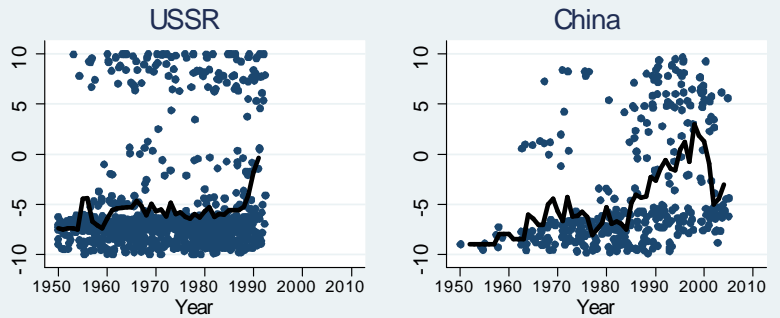

- Polity of destination Mean polity of all destinations

Note: To make it easier to see the density when plotting discrete variables, the locations of the markers are slightly perturbed.

Figure 9: Polity of export destinations for six key players, 1950-2007.

\subsection{Trends in Democratisation}

Before proceeding with the regressions, it is useful to take a first look at the data by studying trends in the variables and plotting key relationships. Figure 8 depicts the evolution of the sample size and the average polity over the sample period. The left graph shows that over the period 1950-2007, sample size displays a positive trend, implying that an increasing number of countries are trading arms. The trend is particularly strong until the beginning of the 1980s. During the 1980s, the trend is in fact decreasing but starts to increase again in the middle of the 1990s. This pattern holds for the NATO network as well as for the overall network. The trend for the Warsaw Pact is increasing until its disestablishment in 1991.

The right graph in Figure 8 captures the average POLITY-scores in the entire sample and in the two subgroups. A positive POLITY index indicates that the sample is democratic on average, while a negative value indicates that the sample is non-democratic according to the POLITY IV criteria. The results suggest the NATO network was, on average, democratic 
in the beginning of the 1950s, but became less democratic in the 1960s and 1970s. In the early 1980s, democratisation picked up and the average POLITY-score of the NATO network again displayed a positive trend. The trend for the Warsaw Pact is increasing, but the average POLITY-score remains negative throughout the existence of this network. These results suggest that a country trading arms with members of the Warsaw Pact, was indeed non-democratic on average. The trend for the overall sample closely follows that of the NATO network since NATO comprised more countries. ${ }^{13}$

We next address the question of whether countries are more likely to export arms to countries with the same polity. Figure 9 displays the POLITY-scores of the export destinations of the US, the UK, France, Sweden, the USSR and China over the period 1950-2007. Each dot represents the POLITY-score of each export destination in a given year and the black line indicates the per-year average. The top left graph of the US shows that the world's oldest democracy has consistently been prone to export arms to other democracies. However, as the graph shows, the US has also exported arms to autocratic countries throughout the sample period. There is a positive trend in the plot for the US, indicating that the US has chosen to export arms to countries that have become increasingly democratic. However, this could just be symptomatic of the overall tendency to world democratisation rather than of the US becoming increasingly choosy when deciding which countries to export to. The patterns for the UK, France and Sweden are more erratic. The UK and France have been prone to export arms to other democracies except for in the 1970s and, in the case of France up to the mid-1980s. Sweden has mainly stayed on the democratic-side of the horizontal axis except for in a few years in the late 1970s when there was a tendency to export arms to non-democracies, albeit with average POLITY-scores close to zero.

By contrast, the USSR and China have typically exported arms to other autocratic countries. The data suggest that they have exported arms to democracies as well, but the average trading partner has been non-democratic. There is some evidence that China started exporting more arms to democratic countries in the beginning of the 21th century, but the trend has

\footnotetext{
${ }^{13}$ Figure A4 in the Appendix plots the sample size along with the average polity within the sub-network of countries trading in 1950. While sample size is decreasing, average polity displays a positive trend. The original traders of 1950 thus also tend to become more democratic over time.
} 
been reversed in recent years.

The results also suggest that, compared to NATO members, the USSR and China have been relatively more prone to export arms to countries with similar POLITY-scores. This indicates that, in the sample, autocracies have an even stronger bias towards other autocracies than democracies vis-à-vis other democracies.

\subsection{The Gravity Equation}

As reported in the previous section, plotting the data suggests that there is a correlation between polity divergence and arms trade. To formally test this hypothesis, we include distance in POLITY-scores as an explanatory variable in a gravity specification, controlling for a wide range of factors that may influence the choice of trading partners. Throughout the regression analysis, we estimate linear probability models with and without importer and exporter fixed effects. ${ }^{14}$

Suppose that we have $i=1, \ldots, N$ countries in the sample. Let $A_{i j}$ and $\vec{A}_{i j t}$ be dichotomous variables such that

$$
A_{i j t}=\left\{\begin{array}{c}
1 \text { if countries } i \text { and } j \text { trade in arms at time } t \\
0 \text { otherwise }
\end{array}\right.
$$

and

$$
\vec{A}_{i j t}=\left\{\begin{array}{c}
1 \text { if country } i \text { exports arms to country } j \text { at time } t \\
0 \text { otherwise }
\end{array} .\right.
$$

We define the variable $B_{i j t}$ as assuming the value 1 if $i$ and $j$ share the same border (contiguity), $L_{i j t}$, assuming the value 1 if $i$ and $j$ share the same official language, $C R_{i j t}$, assuming the value 1 if $i$ and $j$ were ever in a colonial relationship, $C C_{i j t}^{45}$, assuming the value 1 if the countries were colonised by the same country post-1945, $C R_{i j t}^{45}$, assuming the value 1 if the countries were in a colonial relationship post-1945 and finally, $S C_{i j t}$, assuming the value 1 if the countries were

\footnotetext{
14 The empirical trade literature has recently paid attention to the absence of trade between many countries, even at the aggregate level. Helpman et al. (2008) report that as many as half of all aggregate bilateral trade flows assume the value zero (these are often dropped from the sample by researchers using logarithmic values) and suggest a structural estimation procedure building on firm heterogeneity as in Melitz (2003). However, we do not believe firm heterogeneity to be the driving force behind arms trade and find a linear probability approach more appropriate.
} 
the same country historically. Let $D_{i j t}$ denote distance between $i$ and $j$, let $Y_{i t} Y_{j t}$ denote the product of $G D P$ in country $i$ and $j$, let $Y_{i t}^{C} Y_{j t}^{C}$ denote the product of $G D P$ per capita in country $i$ and $j$, and let $R Y_{i j t}^{C}$ be relative GDP per capita between $i$ and $j$, i.e. $R Y_{i j t}^{C}=Y_{i t}^{C}-Y_{j t}^{C}$. Finally, let $P_{i t}$ be the POLITY-score of country $i$ at time $t$. We then estimate the following linear probability models:

$$
A_{i j t}=\alpha\left(P_{i t}-P_{j t}\right)^{2}+\bar{\beta} X_{i j t}+\epsilon_{i j t}
$$

$\forall i<j$ and

$$
\vec{A}_{i j t}=\alpha\left(P_{i t}-P_{j t}\right)^{2}+\bar{\beta} X_{i j t}+\sum_{i=1}^{N}\left(\gamma_{X i} d_{X i}+\gamma_{M i} d_{M i}\right)+\epsilon_{i j t}
$$

$\forall i \neq j$ where $\bar{\beta}$ is a vector of parameters and $X_{i j t}$ is a vector of controls described above. ${ }^{15} \mathrm{~A}$ significant negative estimate of $\alpha$ thus suggests that the more different $i$ and $j$ are in terms of polity, the less likely they are to trade in arms. The dummy variables $d_{X i}$ and $d_{M i}$ assume the value 1 if country $i$ is the exporter and importer, respectively, and 0 otherwise. ${ }^{16}$

We thus estimate gravity models with and without importer and exporter fixed effects. It is not obvious whether fixed effects should be included. Fixed effects will capture all countryspecific differences some of which may be of great importance to arms trade. Therefore, the estimation without fixed effects measures the general correlation between differences in polity and likelihood to trade in arms, but disregards country-specific characteristics. Some countries, such as the US or the UK, may for instance be more involved in arms trade due the magnitude of their domestic arms trade industries and some countries may be trading extensively due to being endowed with much military equipment, such as the Ukraine after the breakup of the USSR. Models without fixed effects also fail to take into account whether countries exhibiting

\footnotetext{
${ }^{15}$ The set of control variables could possibly be augmented to include alliance affiliation and measures of the network chacracteristics. Including the latter might admittedly provide an interesting connection between the network analysis and the regression analysis. However, as with alliance affiliation, variables capturing the network characteristics are endogenous to the dependent variable and including them would not be meaningful.

${ }^{16}$ We do not apply country-pair fixed effects to the gravity equation since our outcome variable is binary, i.e. measures whether trade occurs or not, and therefore does not contain enough variation. Moreover, the empirical trade literature has recently paid attention to the absence of trade between many countries, even at the aggregate level. Helpman et al. (2008) report that as many as half of all aggregate bilateral trade flows assume the value zero (these are often dropped from the sample by researchers using logarithmic values) and suggest a structural estimation procedure building on firm heterogeneity as in Melitz (2003). However, we do not believe firm heterogeneity to be the driving force behind arms trade and find a linear probability approach more appropriate.
} 
high risk of military conflict, such as the Koreas or Turkey, are more prone to import arms. When fixed effects are included, the estimate $\alpha$ will show the effect of differences in polity on the likelihood of arms trade taking such country-specific effects into account.

Since far from all countries trade in arms and since the POLITY-score fluctuates greatly with $\max \left(P_{i t}-P_{j t}\right)^{2}=400$, our estimates of $\alpha$ are likely to be quantitatively small and are unlikely to accurately reveal the importance of distance in polity for the likelihood of arms trade. In order to provide meaningful interpretations of the extimated $\alpha$-coefficients, we convert them into implied relative probabilities by taking into account the maximum variation of the POLITY-score and by relating the probability that two countries with different polities trade in arms to the probability that any two countries trade in arms. For the estimations without fixed effects we compute the implied relative likelihood, $\widehat{\theta}$, as follows:

$$
\widehat{\theta}=-\frac{\left(P_{\max }-P_{\min }\right)^{2} \widehat{\alpha}}{\rho_{\text {arms }}}
$$

where $P_{\max }$ and $P_{\min }$ are the maximum and minimum POLITY-scores, respectively, $\widehat{\alpha}$ is the estimate from (9) and $\rho_{\text {arms }}$ is the empirical probability that arms trade occurs in the sample. At each point in time, the probability of arms trade is given by

$$
\rho_{\text {arms }}=\sum_{i} \sum_{i<j} \frac{A_{i j}}{N(N-1) / 2}
$$

where $A_{i j}$ is defined above and $N$ is the number of countries. For the fixed effects estimations the implied relative likelihood is computed in the same way, but the average probability is slightly modified since the sample size increases when the direction of trade is taken into account.

The implied relative likelihood, $\widehat{\theta}$, thus measures how much less likely it is that two countries with the maximum distance in polity trade in arms than two countries with the minimum distance in polity when the overall probability of arms trade is taken into account.

As mentioned in the introduction, trade in arms is likely to exhibit some unique properties that separates it from trade in any other good. In an attempt to identify the effects of these unique features of arms trade, we estimate (9) also for aggregate trade in non-military goods. 


\subsection{Results}

The results from estimating (9) and (10) using pooled OLS on the full sample 1950-2007 are displayed in Table 1. Columns (1)-(3) display the results without fixed effects, i.e. model (9), and columns (4)-(6) the results when exporter and importer fixed effects are included as in model (10). Columns (7)-(10) report results from estimating the same models on the Cold War and post-Cold War subsamples.

The results in columns (1)-(3) suggest that differences in polity have a negative effect on the likelihood of arms trade. If the difference in POLITY-scores between countries $i$ and $j$ is high, they are less likely to engage in arms trade. The implied relative likelihood, computed according to (11), indicates that the effects are large. A country with the highest possible POLITY-score, is approximately 60 percent less likely to trade with a country with the lowest possible polity score than with a country that receives the highest possible polity rating. Columns (4)-(6) indicate that these findings are robust to the inclusion of importer and exporter fixed effects. Even when taking into account fixed country characteristics such as the size of the arms industry and proximity to war zones, countries are more likely to trade with states in their political vicinity

In light of the dramatic changes in the arms trade network structure discussed in Section 2 , it is of great interest to study whether the effect of polity on the likelihood of arms trade is stable over time. Figure 10 displays the implied relative likelihood derived from the $\alpha$ coefficients obtained when estimating (9) and (10) and the associated 95-percent confidence interval in each year. The left panel shows the results without fixed effects and the right panel the results with importer and exporter fixed effects.

The results without fixed effects suggest that the estimate for arms trade is negative and significantly different from zero for almost every year in the sample. The negative likelihood decreases somewhat over time but remains negative throughout the sample period. When including fixed effects in the right panel, we see that the effect of distance in polity remains negative for the duration of the Cold War but tends to zero after 1990 . 
Table 1: Results from estimating the gravity equation. Pooled OLS.

\begin{tabular}{|c|c|c|c|c|c|c|c|c|c|c|}
\hline \multirow[t]{2}{*}{ Sample } & \multicolumn{6}{|c|}{$1950-2007$} & \multicolumn{2}{|c|}{ 1950-1989 } & \multicolumn{2}{|c|}{$1990-2007$} \\
\hline & (1) & $(2)$ & (3) & (4) & (5) & (6) & (7) & (8) & (9) & (10) \\
\hline$\left(P_{i t}-P_{j t}\right)^{2}$ & $\begin{array}{r}-.046^{* *} \\
(.002)\end{array}$ & $\begin{array}{r}-.044^{* *} \\
(.002)\end{array}$ & $\begin{array}{l}-.042^{* *} \\
(.002)\end{array}$ & $\begin{array}{r}-.046^{* *} \\
(.001)\end{array}$ & $\begin{array}{r}-.025^{* *} \\
(.001)\end{array}$ & $\begin{array}{c}-.023^{* *} \\
(.001)\end{array}$ & $\begin{array}{r}-.068 * * \\
(.003)\end{array}$ & $\begin{array}{r}-.040^{* *} \\
(.002)\end{array}$ & $\begin{array}{r}-.029 * * \\
(.004)\end{array}$ & $\begin{array}{r}-.003 \\
(.002)\end{array}$ \\
\hline $\ln \left(Y_{i t} Y_{i t}\right)$ & $\begin{array}{l}.018^{* *} \\
(.000)\end{array}$ & $\begin{array}{l}.013^{* *} \\
(.000)\end{array}$ & $\begin{array}{l}.014^{* *} \\
(.000)\end{array}$ & $\begin{array}{l}.003^{* *} \\
(.000)\end{array}$ & $\begin{array}{r}-.001^{* *} \\
(.000)\end{array}$ & $\begin{array}{l}.001^{* *} \\
(.000)\end{array}$ & $\begin{array}{l}.016^{* *} \\
(.000)\end{array}$ & $\begin{array}{l}.004^{* *} \\
(.000)\end{array}$ & $\begin{array}{l}.010^{* *} \\
(.000)\end{array}$ & $\begin{array}{r}-.012^{* *} \\
(.001)\end{array}$ \\
\hline $\ln \left(Y_{i t}^{C} Y_{j t}^{C}\right)$ & & $\begin{array}{l}.001^{* *} \\
(.000)\end{array}$ & $\begin{array}{l}.001^{* *} \\
(.000)\end{array}$ & & $\begin{array}{l}.000 * * \\
(.000)\end{array}$ & $\begin{array}{l}.000^{* *} \\
(.000)\end{array}$ & $\begin{array}{l}.000^{* *} \\
(.000)\end{array}$ & $\begin{array}{l}.000^{* *} \\
(.000)\end{array}$ & $\begin{array}{l}.001^{* *} \\
(.000)\end{array}$ & $\begin{array}{l}.001^{* *} \\
(.000)\end{array}$ \\
\hline $\ln \left(R Y_{i j t}^{C}\right)^{2}$ & & & $\begin{array}{l}.000^{* *} \\
(.000)\end{array}$ & & & $\begin{array}{r}-.002^{* *} \\
(.000)\end{array}$ & $\begin{array}{l}.001^{* *} \\
(.000)\end{array}$ & $\begin{array}{r}-.002^{* *} \\
(.000)\end{array}$ & $\begin{array}{l}.000^{* *} \\
(.000)\end{array}$ & $\begin{array}{l}.001^{* *} \\
(.000)\end{array}$ \\
\hline $\ln D_{i j}$ & $\begin{array}{r}-.012^{* *} \\
(.000)\end{array}$ & $\begin{array}{r}-.007^{* *} \\
(.000)\end{array}$ & $\begin{array}{l}-.007^{* *} \\
(.000)\end{array}$ & $\begin{array}{r}-.003^{* *} \\
(.000)\end{array}$ & $\begin{array}{r}-.001^{* *} \\
(.000)\end{array}$ & $\begin{array}{l}.000^{* *} \\
(.000)\end{array}$ & $\begin{array}{r}-.011^{* *} \\
(.001)\end{array}$ & $\begin{array}{r}-.001^{* *} \\
(.000)\end{array}$ & $\begin{array}{r}-.003^{* *} \\
(.001)\end{array}$ & $\begin{array}{l}.002^{* *} \\
(.000)\end{array}$ \\
\hline$B_{i j}$ & $\begin{array}{l}.025^{* *} \\
(.002)\end{array}$ & $\begin{array}{l}.031^{* *} \\
(.002)\end{array}$ & $\begin{array}{l}.030^{* *} \\
(.002)\end{array}$ & $\begin{array}{r}.025^{* *} \\
(.001)\end{array}$ & $\begin{array}{l}.023^{* *} \\
(.001)\end{array}$ & $\begin{array}{l}.023^{* *} \\
(.001)\end{array}$ & $\begin{array}{l}.028^{* *} \\
(.003)\end{array}$ & $\begin{array}{l}.023^{* *} \\
(.001)\end{array}$ & $\begin{array}{l}.033^{* *} \\
(.003)\end{array}$ & $\begin{array}{l}.021^{* *} \\
(.002)\end{array}$ \\
\hline$L_{i j}$ & $\begin{array}{l}.006^{* *} \\
(.001)\end{array}$ & $\begin{array}{l}.006^{* *} \\
(.001)\end{array}$ & $\begin{array}{l}.006^{* *} \\
(.001)\end{array}$ & $\begin{array}{r}-.001^{* *} \\
(.000)\end{array}$ & $\begin{array}{l}.000^{* *} \\
(.000)\end{array}$ & $\begin{array}{l}.001^{* *} \\
(.000)\end{array}$ & $\begin{array}{l}.004^{* *} \\
(.001)\end{array}$ & $\begin{array}{c}-.001^{*} \\
(.001)\end{array}$ & $\begin{array}{l}.004^{* *} \\
(.002)\end{array}$ & $\begin{array}{l}.004^{* *} \\
(.001)\end{array}$ \\
\hline$C R_{i j}$ & $\begin{array}{l}.118^{* *} \\
(.004)\end{array}$ & $\begin{array}{l}.110^{* *} \\
(.004)\end{array}$ & $\begin{array}{l}.110^{* *} \\
(.004)\end{array}$ & $\begin{array}{l}.063^{* *} \\
(.002)\end{array}$ & $\begin{array}{l}.060 * * \\
(.002)\end{array}$ & $\begin{array}{l}.059^{* *} \\
(.002)\end{array}$ & $\begin{array}{l}.131^{* *} \\
(.005)\end{array}$ & $\begin{array}{l}.071^{* *} \\
(.002)\end{array}$ & $\begin{array}{l}.052^{* *} \\
(.006)\end{array}$ & $\begin{array}{l}.028^{* *} \\
(.003)\end{array}$ \\
\hline$C C_{i j}^{45}$ & $\begin{array}{r}.001 \\
(.001)\end{array}$ & $\begin{array}{r}.002 \\
(.001)\end{array}$ & $\begin{array}{l}.002 \\
(.001)\end{array}$ & $\begin{array}{l}.003^{* *} \\
(.001)\end{array}$ & $\begin{array}{l}.001 * \\
(.001)\end{array}$ & $\begin{array}{r}.000 \\
(.001)\end{array}$ & $\begin{array}{l}.004^{*} \\
(.001)\end{array}$ & $\begin{array}{l}.002^{* *} \\
(.001)\end{array}$ & $\begin{array}{r}.003 \\
(.002)\end{array}$ & $\begin{array}{l}-.002^{*} \\
(.001)\end{array}$ \\
\hline$C R_{i j}^{45}$ & $\begin{array}{l}.060^{* *} \\
(.005)\end{array}$ & $\begin{array}{l}.072^{* *} \\
(.005)\end{array}$ & $\begin{array}{l}.074^{* *} \\
(.005)\end{array}$ & $\begin{array}{r}-.037^{* *} \\
(.002)\end{array}$ & $\begin{array}{r}-.030 * * \\
(.002)\end{array}$ & $\begin{array}{r}-.027^{* *} \\
(.002)\end{array}$ & $\begin{array}{l}.108^{* *} \\
(.006)\end{array}$ & $\begin{array}{r}-.018^{* *} \\
(.003)\end{array}$ & $\begin{array}{l}.016^{*} \\
(.008)\end{array}$ & $\begin{array}{r}-.036^{* *} \\
(.004)\end{array}$ \\
\hline$S C_{i j}$ & $\begin{array}{r}-.037^{* *} \\
(.003)\end{array}$ & $\begin{array}{r}-.032^{* *} \\
(.003)\end{array}$ & $\begin{array}{l}-.032^{* *} \\
(.003)\end{array}$ & $\begin{array}{r}-.013^{* *} \\
(.002)\end{array}$ & $\begin{array}{r}-.012^{* *} \\
(.001)\end{array}$ & $\begin{array}{r}-.012^{* *} \\
(.001)\end{array}$ & $\begin{array}{r}-.031^{* *} \\
(.004)\end{array}$ & $\begin{array}{r}-.012^{* *} \\
(.002)\end{array}$ & $\begin{array}{r}-.030^{* *} \\
(.005)\end{array}$ & $\begin{array}{r}-.008^{* *} \\
(.003)\end{array}$ \\
\hline$\widehat{\theta}^{1}$ & $63^{* *}$ & $61^{* *}$ & $57 * *$ & $123^{* *}$ & $66^{* *}$ & $61^{* *}$ & $88^{* *}$ & $100^{* *}$ & $46^{* *}$ & 8 \\
\hline $\mathrm{FE}^{2}$ & No & No & No & Yes & Yes & Yes & No & Yes & No & Yes \\
\hline $\begin{array}{l}N \\
R^{2}\end{array}$ & $\begin{array}{r}313925 \\
.098\end{array}$ & $\begin{array}{r}313925 \\
.117\end{array}$ & $\begin{array}{l}313925 \\
.117\end{array}$ & $\begin{array}{r}632799 \\
.194\end{array}$ & $\begin{array}{r}632799 \\
.201\end{array}$ & $\begin{array}{r}632799 \\
.202\end{array}$ & $\begin{array}{r}203089 \\
.123\end{array}$ & $\begin{array}{r}409561 \\
.221\end{array}$ & $\begin{array}{r}102961 \\
.128\end{array}$ & $\begin{array}{r}207362 \\
.180\end{array}$ \\
\hline
\end{tabular}

\footnotetext{
${ }^{1}$ Standard-errors within parenthesis. Significant codes: $* *$ significant at the 1 percent level; $*$ significant at the 5 percent level. The coefficient and standard error for distance in polity is multiplied by 1000 .

${ }^{2}$ The implied relative likelihood of arms trade in percent. Measures how much less likely it is that two countries with the maximum deviation in polity trade in arms compared to two countries with the same polity.

${ }^{3}$ Exporter and importer fixed effects.
} 


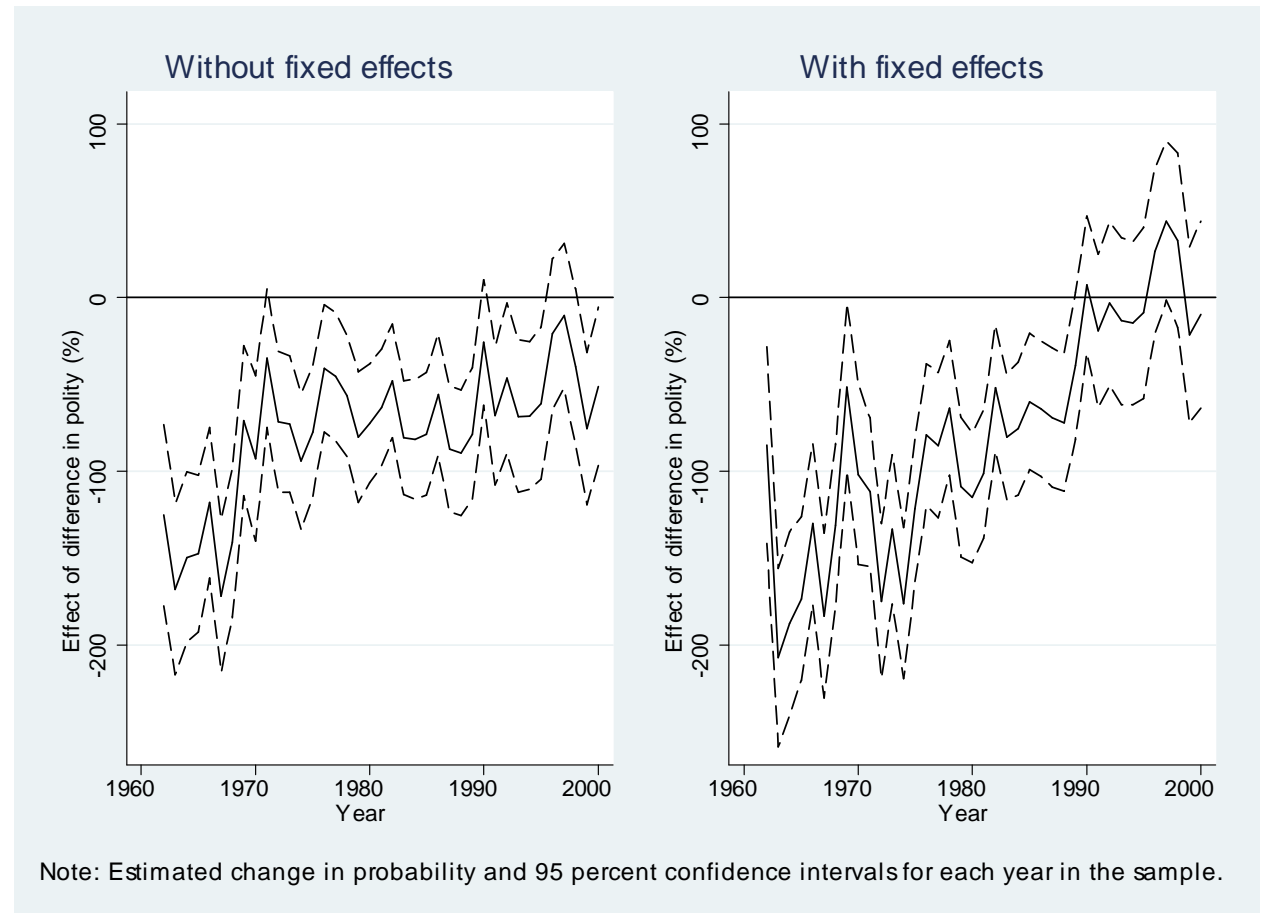

Figure 10: Polity divergence and arms trade.

How can we reconcile these findings? Recall that fixed effects allow us to control for countryspecific characteristics such as the size of the arms trade industry and the technology available and that the fixed effects therefore are likely to proxy for the extent of trade. Excluding fixed effects implies that any effect of polity that we observe may be due to selection: perhaps democratic countries happen to trade with democratic countries simply because the latter group tends to produce arms. Including fixed effects, however, allows us to purge the estimates of such effects. The results in the right panel in Figure 9 thus suggest that, even when controlling for country characteristics, arms traders chose to trade with states with similar polity throughout the Cold War. We may thus conclude that it is the political regime and not other circumstances that is the driving force behind these trade alliances. After 1990, however, any negative correlation between distance in polity and the likelihood of arms trade that we find, is entirely absorbed by the country-specific fixed effects. The political regime, it seems, therefore played an important role prior to the fall of the Soviet Union but has been of no importance in recent years. This is a key finding. 


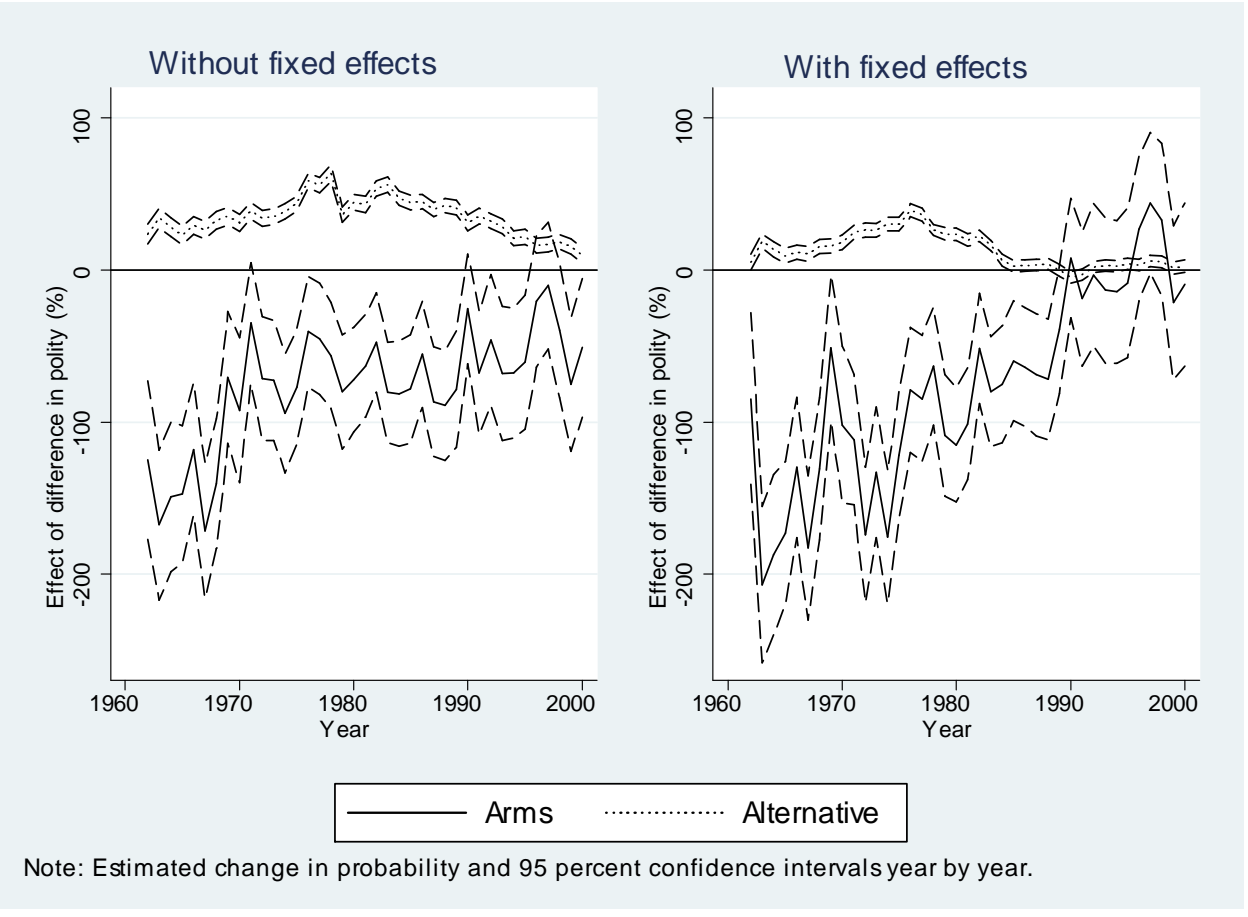

Figure 11: Polity divergence and aggregate trade in goods.

Columns (7) and (8) report the results from estimating (9) and (10) on the Cold War sub-sample 1950-1989. The estimates corroborate the annual estimates depicted in Figures 9 and 10. Differences in polity has a significant, negative effect on the likelihood of arms trade prior to 1990. Columns (9) and (10) repeat this exercise on the post-1990 sample. The results confirm our previous findings that any effects of distance in polity that we find can be accounted for by exporter and importer fixed effects. This suggests that the importance of polity has decreased over time and has in fact vanished completely in the last two decades.

As a robustness check, we also estimate (9) and (10) for aggregate trade to see whether distance in polity has any impact on the likelihood of trade in non-military goods. To be able to compare the two, we plot the results for arms trade along with the corresponding implied likelihood for aggregate trade in other goods in Figure 10. We find no negative effects of distance in polity on the likelihood of aggregate trade. The correlation is positive before 1990 and then tends to zero. The positive correlation found for aggregate trade may be driven by factors unrelated to polity, such as comparative advantage, factor endowments or natural 
resources. ${ }^{17}$

\section{Concluding Remarks}

In this paper, we study the evolution of the global arms trade network using a unique dataset on all international transfers of major conventional weapons over the period 1950-2007. The analysis consists of two parts. First, we characterise global arms trade over the sample period, using methods from social network analysis. Second, we address the relationship between distance in POLITY-scores and likelihood of arms trade, using a gravity equation augmented by political and economic controls.

The first part of the analysis reveals that the arms trade network shares common traits with other networks, notably a small world property, negative correlation between degree and clustering coefficients and a scale-free degree distribution. Moreover, the network exhibits negative assortativity, a property found to characterise other trade networks as well.

The data mirrors common views of the ideological divide of the Cold War. There is a clear division between NATO and the Warsaw Pact until the disestablishment of the latter in 1991. Moreover, the Warsaw Pact is more centered around the Soviet Union than NATO around the US; the Warsaw Pact thus closely resembles a star network with a number of peripheral traders interacting almost exclusively with the USSR.

The sharp dichotomy between NATO and the Warsaw Pact is an indication that, historically, political rule has been a key determinant when choosing arms trading partners. In the second part of the analysis we seek to quantify this relationship by relating distance in POLITY-scores to the likelihood of arms trade. Estimating a gravity equation on the full sample, we find evidence that differences in polity have a significant, negative effect on the likelihood that arms trade occurs. Estimating the relationship for each year in the sample, reveals that the negative relationship is stable throughout the Cold War. After the collapse of the Soviet Union, however, any effects that we observe can be explained by the inclusion of exporter and importer fixed effects.

\footnotetext{
${ }^{17}$ Oil is an obvious example of a good that, to a large extent, is produced in autocratic countries. Since all economies are oil dependent, democracies cannot afford to discriminate against non-democratic exporters when importing this good.
} 
Our results thus suggest that, throughout the Cold War, states deliberately chose to trade with countries within their political vicinity, even after taken into account country-specific characteristics such as the size of the arms industry and geographic location. The importance of polity has, however, diminished greatly over time. Polity, it seems, no longer matters for arms trade decisions after 1990. The evidence suggests that democracies are still inclined to trade with democracies and vice versa, but this selection is not driven by similarities in polity. The propensity for countries to trade with states with similar political rule may be due to some type of habit formation in arms imports. Due to technological constraints, a certain category of arms may not be compatible with products from another country and it may therefore be that once a trade alliance is formed, the relationship is, by necessity, sustained over the long term. 


\section{References}

Aumann, R. J., M. Maschler, and R. Stearns (1968): "Repeated Games of Incomplete Information: an Approach to the Non-Zero Sum Case," Report of the U.S. Arms Control and Disarmament Agency ST-143, Chapter IV, 117-216.

Ayanian, R. (1986): "Nuclear Consequences of the Welfare State," Public Choice, 49(3), $201-222$.

BAliga, S., And T. SJÖStrÖM (2004): "Arms Races and Negotiations," Review of Economic Studies, 71(2), 351-369.

Brito, D. L., and M. D. Intriligator (1981): "Strategic Arms Limitation Treaties and Innovations in Weapons Technology," Public Choice, 37(1), 41-59.

Brzoska, M., and F. S. Pearson (1994): Arms and Warfare: Escalation, De-escalation, and Negotiation. University of South Carolina Press.

Buzan, B., and E. Herring (1998): The Arms Dynamic in World Politics. Lynne Rienner Publishers, Boulder, Colorado.

Cowen, T. (1990): "Economic Effects of a Conflict-Prone World Order," Public Choice, 64(2), $121-134$.

De Benedictis, L., and L. Tajoli (2008): "The World Trade Network," University of Macerata, mimeo.

de Mesquita, B. B., J. D. Morrow, R. M. Siverson, and A. Smith (1999): "An Institutional Explanation of the Democratic Peace," American Political Science Review, 93(4), 791-807.

De Nooy, W., A. Mrvar, and V. Batagelu (2005): Exploratory Social Network Analysis with Pajek. Cambridge University Press, New York.

Flandreau, M., and C. Jobst (2005): "The Ties That Divide: a Network Analysis of the International Monetary System, 1890-1910," The Journal of Economic History, 65(4), 977-1007.

(2009): "The Empirics of International Currencies: Network Externalities, History and Persistence," The Economic Journal, 119(537), 643-664.

Goyal, S., M. J. Van Der LeiJ, and J. L. Moraga-GonzÁlez (2006): "Economics: an Emerging Small World," Journal of Political Economy, 114(2), 403-412.

Helpman, E., M. J. Melitz, and Y. Rubinstein (2008): "Estimating Trade Flows: Trading Partners and Trading Volumes," Quarterly Journal of Economics, 123(2), 441-487.

Intriligator, M. D. (1975): "Strategic Considerations in the Richardson Model of Arms Races," The Journal of Political Economy, 83(2), 339-353. 
Jackson, M. O. (2008): Social and Economic Networks. Princeton University Press.

Kadera, K. M., M. J. C. Crescenzi, and M. L. Shannon (2003): "Democratic Survival, Peace, and War in the International System," American Journal of Political Science, 47(2), $234-247$.

Levine, P., And R. Smith (1995): "The Arms Trade and Arms Control," The Economic Journal, 105(429), 471-484.

Levine, P., R. Smith, L. Reichlin, and P. Rey (1997): "The Arms Trade," Economic Policy, 12(25), 335-370.

Levy, G., And R. Razin (2004): "It Takes Two: an Explanation for the Democratic Peace," Journal of the European economic Association, 2(1), 1-29.

Maoz, Z., and B. Russett (1993): "Normative and Structural Causes of Democratic Peace, 1946-1986," American Political Science Review, 87(3), 624-638.

Melitz, M. J. (2003): "The Impact of Trade on Intra-Industry Reallocations and Aggregate Industry Productivity," Econometrica, 71(6), 1695-1725.

Mulligan, C. B., R. Gil, and X. Sala-i Martin (2004): "Do Democracies Have Different Public Policies than Nondemocracies?," Journal of Economic Perspectives, 18(1), 51-74.

Newman, M. E. (2002): “Assortative Mixing in Networks," Physical Review Letters, 89(20), $1-4$.

Schelling, T. C. (1960): The Strategy of Conflict. Harvard University Press, Cambridge MA. 


\section{Appendix}

Table A1: Member Countries of NATO and the Warsaw Pact.

\begin{tabular}{lclll}
\hline \hline NATO & & & & \\
& Entry & The Warsaw Pact & Entry & Exit \\
\hline Belgium & 1949 & People's Republic of Albania & 1955 & 1961 \\
Denmark & 1949 & People's Republic of Bulgaria & 1955 & 1991 \\
France & 1949 & Czechoslovak Socialist Republic & 1955 & 1991 \\
Iceland & 1949 & People's Republic of Hungary & 1955 & 1991 \\
Italy & 1949 & People's Republic of Poland & 1955 & 1991 \\
Canada & 1949 & People's Republic of Romania & 1955 & 1991 \\
Luxembourg & 1949 & The Soviet Union & 1955 & 1991 \\
Netherlands & 1949 & East Germany & 1956 & 1990 \\
Norway & 1949 & & & \\
Portugal & 1949 & & & \\
Great Britain & 1949 & & & \\
USA & 1949 & & & \\
Greece & 1952 & & & \\
Turkey & 1952 & & & \\
(West) Germany & 1955 & & & \\
Spain & 1982 & & & \\
Poland & 1999 & & & \\
Czech Republic & 1999 & & & \\
Estonia & 2004 & & & \\
Latvia & 2004 & & & \\
Lithuania & 2004 & & & \\
Romania & 2004 & & & \\
Slovakia & 2004 & & & \\
Slovenia & 2004 & & & \\
Croatia & 2009 & & & \\
Albania & 2009 & & & \\
& & & & \\
\hline \hline
\end{tabular}




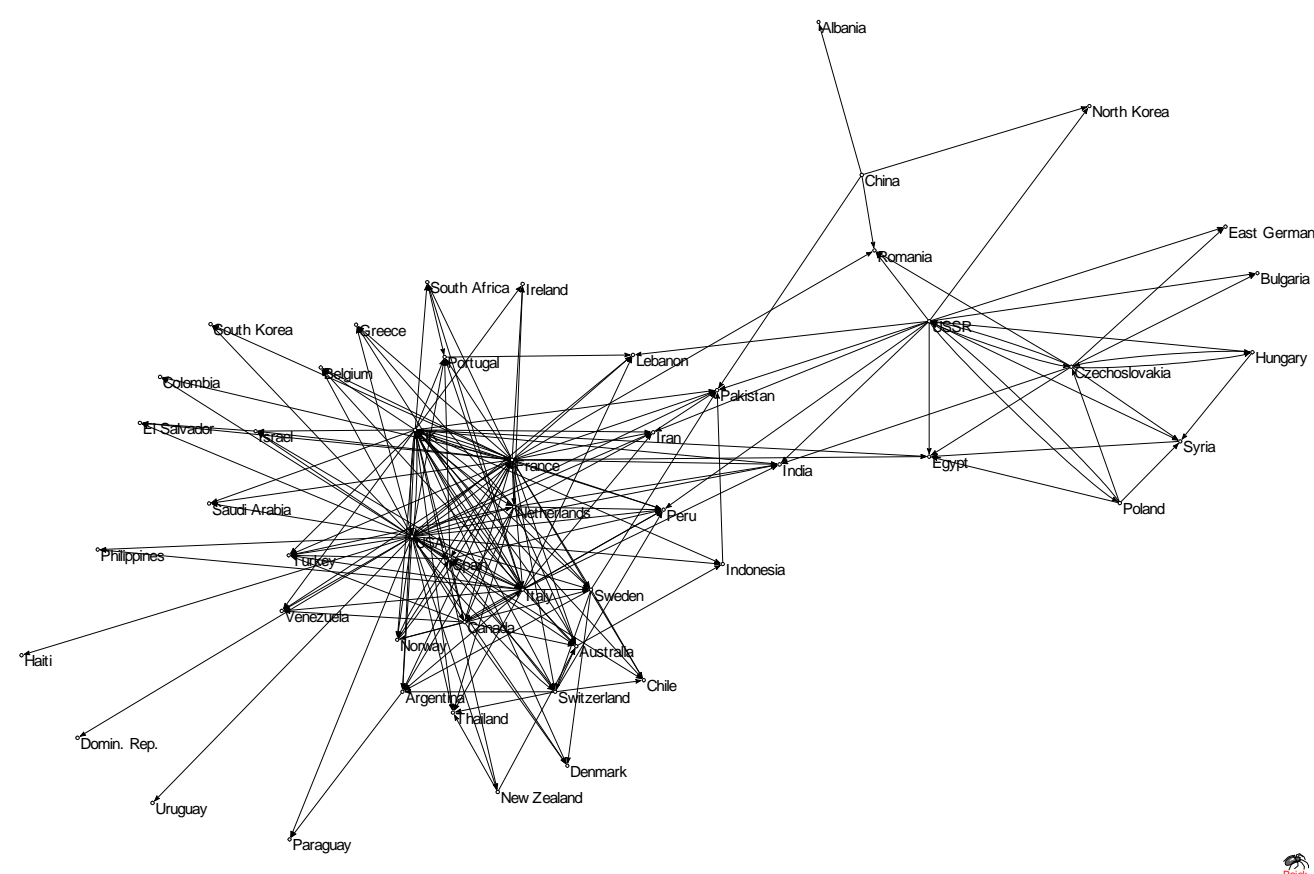

Figure A1: The arms trade network of the subset of countries trading in 1950, 1970-1974. 

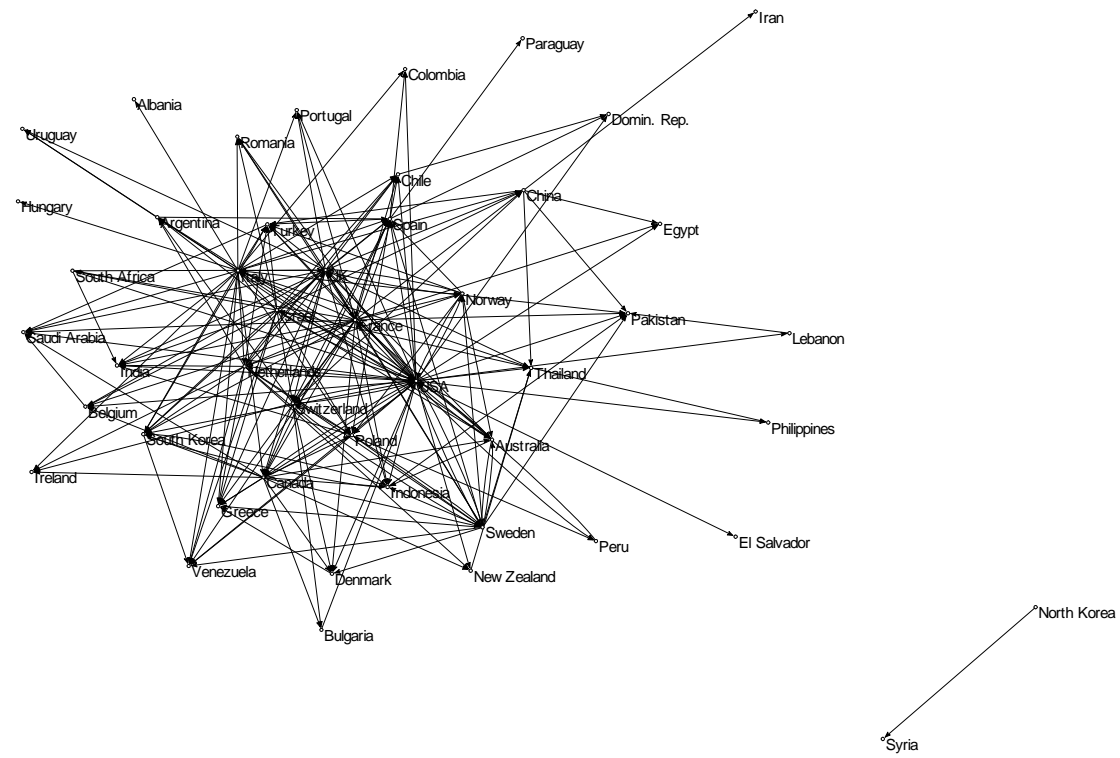

赵

Figure A2: The arms trade network of the subset of countries trading in 1950, 2000-2004. 

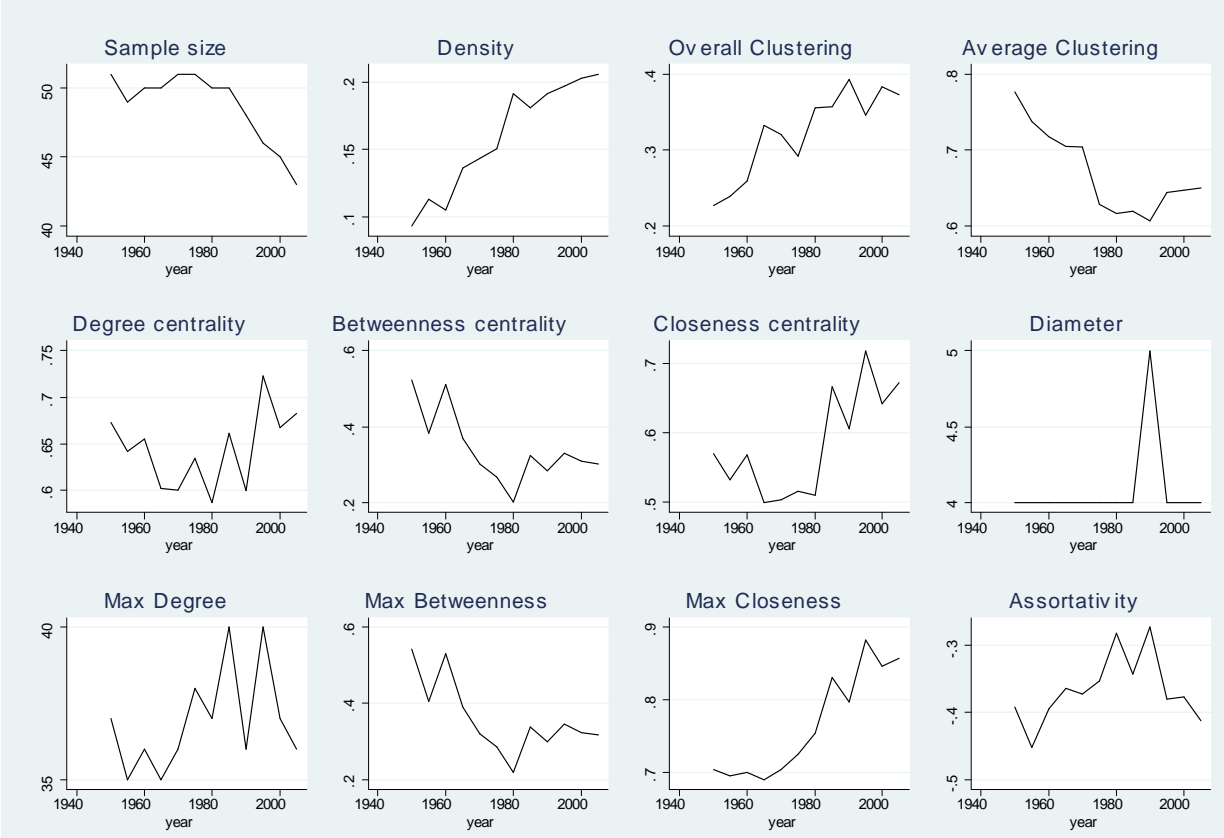

Note: All years and all countries in the sample are included.

Figure A3: Network statistics for the subset of countries trading in 1950. 


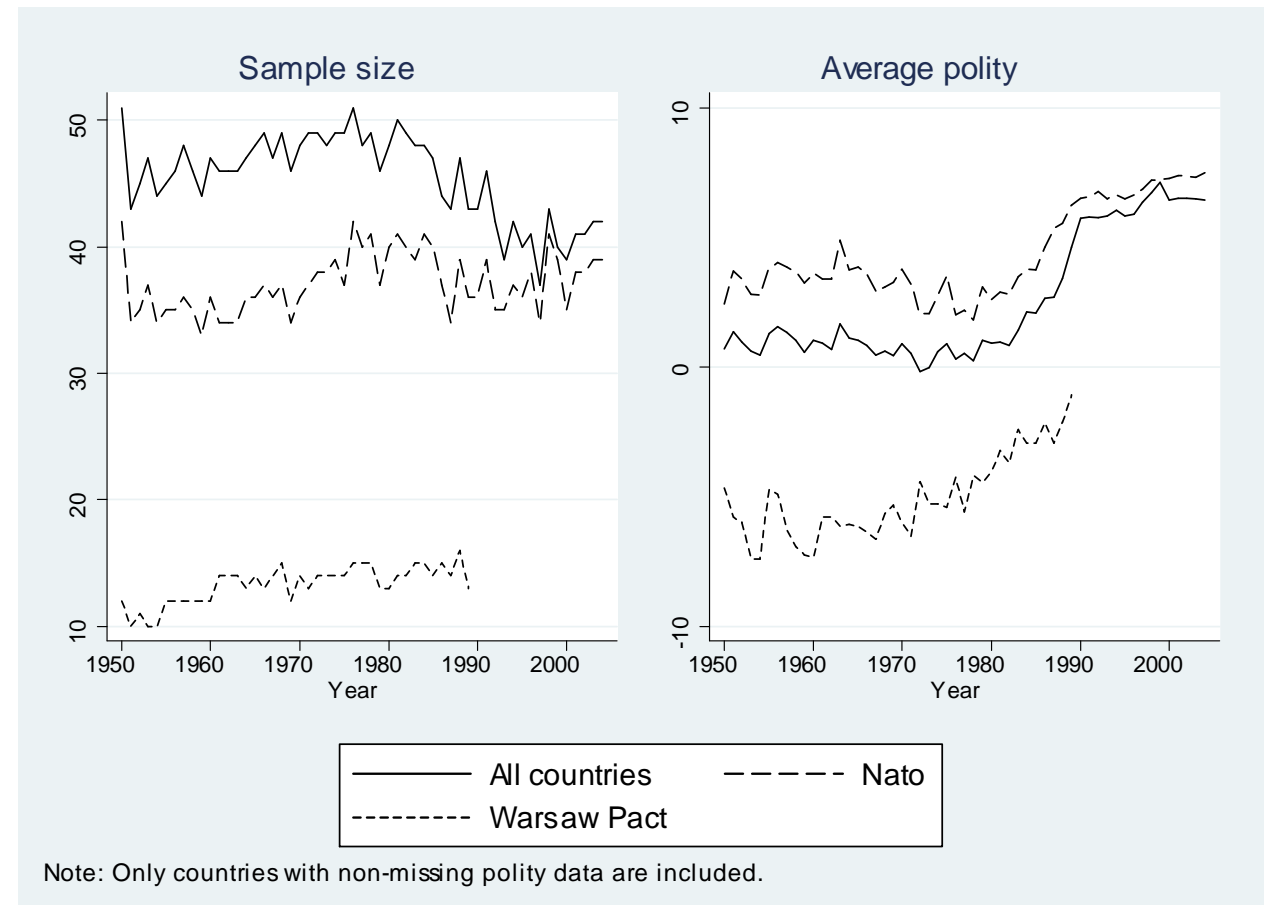

Figure A4: Arms trade participation and average polity, 1950-2007: the subset of countries trading in 1950. 